IZA DP No. 7782

Acquiring Human Capital through the Generations by Migration

James P. Smith

Liam Delaney

November 2013 


\title{
Acquiring Human Capital through the Generations by Migration
}

\author{
James P. Smith \\ RAND Corporation \\ and IZA \\ Liam Delaney \\ University of Stirling
}

\section{Discussion Paper No. 7782 \\ November 2013}

\author{
IZA \\ P.O. Box 7240 \\ 53072 Bonn \\ Germany \\ Phone: +49-228-3894-0 \\ Fax: +49-228-3894-180 \\ E-mail: iza@iza.org
}

Any opinions expressed here are those of the author(s) and not those of IZA. Research published in this series may include views on policy, but the institute itself takes no institutional policy positions. The IZA research network is committed to the IZA Guiding Principles of Research Integrity.

The Institute for the Study of Labor (IZA) in Bonn is a local and virtual international research center and a place of communication between science, politics and business. IZA is an independent nonprofit organization supported by Deutsche Post Foundation. The center is associated with the University of Bonn and offers a stimulating research environment through its international network, workshops and conferences, data service, project support, research visits and doctoral program. IZA engages in (i) original and internationally competitive research in all fields of labor economics, (ii) development of policy concepts, and (iii) dissemination of research results and concepts to the interested public.

IZA Discussion Papers often represent preliminary work and are circulated to encourage discussion. Citation of such a paper should account for its provisional character. A revised version may be available directly from the author. 
IZA Discussion Paper No. 7782

November 2013

\section{ABSTRACT}

\section{Acquiring Human Capital through the Generations by Migration *}

Our focus will be on the role of migration to the United States from a set of important European sending countries as a device for improving the human capital of the children and grandchildren of migrants as measured by their education. In this paper, we derive a new and conceptual more appropriate measure of the generational gains in schooling attributable to migration by taking into account the correct counter-factual - the generational education gains that would have taken place if these migrants had remained in their sending countries. We find that the two European countries where the descendants gained the most in terms of human capital are Italy and Poland.

JEL Classification: $\quad 124,125$

Keywords: human capital, education, migration

Corresponding author:

James P. Smith

RAND Corporation

1776 Main Street

PO Box 2138

Santa Monica, CA 90407

USA

E-mail: smith@rand.org

* This research was supported by grants from the NIA and NICHD at the National Institutes of Health, USA. 
America is rightly described as a nation of migrants. While economic improvement of the migrants themselves has been historically seen as an important motivation for migration to the United States, much less well documented is the role of international migration in improving the economic lot of the children and grandchildren of migrants. In particular, our focus will be on the role of migration to the United States from a set of important European sending countries as a device for improving the human capital of the children and grandchildren of migrants as measured by their education. In this paper, we derive a new and conceptual more appropriate measure of the generational gains in schooling attributable to migration by taking into account the correct counter-factual—the generational education gains that would have taken place if these migrants had remained in their sending countries.

Our research will examine the experience of migrants from seven European nations (England, Scotland, Ireland, Germany, Scandinavia, ${ }^{1}$ Italy, and Poland) which comprised more than 70\% of European migrants coming to the United States between 1850 and 1970. Our American data will rely on the decennial Censuses between 1940 and 1970, Current Population Surveys (CPS) since 1994, the American Community Survey (since 2000), and the General Social Survey since 1994. All these data sources contain information on immigrant status by generation and country of origin as well as education level completed so that the educational accomplishments of all generations of immigrants can be computed. To assess, at least for the $20^{\text {th }}$ century, education trends in the sending European countries, we use five waves of the European Social Survey, conducted between 2002 and 2010. Throughout, we will conduct our analysis separately for men and women

Using this data, we will compute completed years of schooling for each immigrant

\footnotetext{
${ }^{1}$ For our purposes, Scandinavia includes Denmark, Finland, Norway, and Sweden.
} 
generation (first, second, and third or more) which will allow us to measure education progress across the generations for immigrants and their descendants. This data will then be used to derive education gains for children of migrants due to the decision of their parents to migrate compared to education gains that would have taken place if migrants had remained in the sending country. These gains will be largest when education progress in sending countries was slow over time. Our analysis indicates the largest human capital gains associated with migration historically took place with Italian and Polish migrants, while the smallest gains were among English and German migrants. Within countries, the human capital gains due to migration have varied considerably over time.

The remainder of this paper is divided into six sections. The first section describes the magnitude of migration flows from Europe to the United States by time period since 1850 . Section 2 outlines the American data sources that we used and the way that we construct and define European immigrant generations. The third section summarizes our results for education

levels of European immigrants to the United States during the $19^{\text {th }}$ and $20^{\text {th }}$ centuries. The fourth section documents our results for each of our European countries on the amount of education obtained by generation. These results are then used to derive our measure of the education gain of children and grandchildren of migrants due to migration of their parents or grandparents. Section 5 provides relevant evidence on the changing education selectivity of immigrants over times within the European sending countries. The final section highlights our main conclusions.

\section{European Migration to the United States}

In the hundred years between 1850 and 1950, Europeans dominated immigration flows into the United States. These flows are documented in Table 1 by 20 -year time periods for all 
European countries and for the specific countries that will be the focus of our research. ${ }^{2}$ In the 40 years after 1851 with steadily rising numbers within this time period, about 13 million migrants came to the US with over $90 \%$ of these immigrants being of European heritage. The numbers of immigrants increased sharply in the decades surrounding the start of the $20^{\text {th }}$ century with more than twelve million immigrants arriving between 1891 and 1910 with eleven and a half million of those migrants from Europe. Subsequently, immigration gradually subsided as antiimmigration legislation restricted the flows culminating in the Immigration Act of 1924 which placed numerical limits on immigration and established country-specific quotas that favored the traditional European sending countries. With the absence of much economic opportunity, few immigrants came to America during the depression and World War 2 years, but this pattern reversed again after the World War 2. The 1965 Immigration Act repealed the national-origin quotas and quickly ended the era of a hundred year dominance of European immigrants. Compared to the period at the turn of the $20^{\text {th }}$ Century when about $90 \%$ of migrants to America were of European origin, only 13\% of international migrants between 1971 and 1990 were Europeans.

Table 1 also documents the percent of European immigrants who were from the six countries that are the focus of our analysis. Between 1851 and 1870, more than 90\% of European migrants were from Germany, the UK, and Ireland so that the story of American immigrants during those years was largely their story. Even during the next 20 years (1871-1890), two-thirds of European migrants were from those three countries but now they were joined by others with Scandinavian countries in particular making a significant but somewhat smaller contribution as well. Between 1891 and 1930, the two countries with the largest numbers of new immigrants

\footnotetext{
2 For completeness, Table 1 also includes figures on the extent of migration from countries within the Soviet Union but we do not include the Soviet Union in our analysis due to the frequently changing geographic boundaries.
} 
were Italy and Russia. The 1914 Immigration act which set quotas favoring traditional sending countries lead to a renewed influence of traditional Northern European sending countries in the subsequent flows. By the period of 1971-1990, the six countries on which we focus in this paper still comprise about half of all European migrants to the United States.

\section{Constructing the Generations}

To conduct a generational analysis of levels of education completed of European immigrants and their descendents, it is first necessary to define immigrant generations and immigrant ethnicity or original country of origin and combine that information with their year of birth and years of schooling completed. The first decennial Census that records years of schooling is the 1940 Census so that this Census fixes how far into the past an immigrant analysis can reach in the United States. ${ }^{3}$ Our approach relies on cohort-specific means of years of schooling completed pooled across a number of data sources. Since education is largely stable after ages in the mid twenties, our analysis still extends back well into the nineteenth century. ${ }^{4}$

In this research, generations are defined in the following way; 1st generation—born outside the United States; 2nd generation—at least one parent born outside the United States; 3rd generation plus individual and both parents born in the United States but individual claims a European ancestry. In most of the data sets we use, one is not able to distinguish between the third and subsequent generations. ${ }^{5}$ Therefore, while reference is made for convenience to the third generation, this group actually includes all generations beyond the second. Even this simple trichotomy of generations is not available in many data sources. The availability of complete

\footnotetext{
${ }^{3}$ For an earlier treatment by race see Smith (1984). For Hispanic immigrants see Smith (2003), and for Europeans and Asians as a group see Smith (2006).

${ }^{4}$ As is well known, across Census years indicate some increases in education levels completed beyond any reasonable ages of school completion. This education inflation is often attributed to an exaggeration of schooling accomplishments as education norms in a society rise.

${ }^{5}$ Data on this from general social survey suggest that this difference does not appear that large.
} 
immigrant generational education data on these distinctions varies across the data sets used in this research. Appendix Table A documents the full set of data on education by birth cohort by European ancestry by generation used in this research.

First generation (the immigrants themselves) requires information only on country of birth, while second generation requires knowledge of country of birth of parents when the respondent was born in the US. In both of these situations, country of birth determines assigned sending-country ethnicity. Differences between ethnicity using country of birth or stated ethnicity in the first and second generation tends to be small. For example, Smith (2006) reports that for Asians that 96\% of those who said they were Asian were born in an Asian country. This earliest information we have on education of the first and second generations that allows us to compute their levels of education completed is available from all decennial Censuses between 1940 and 1970. After 1970, generations beyond the first were not distinguished in the decennial Censuses. We also used the 1980-2000 Censuses to compute education data by birth cohort for the first generation.

To supplement these Censuses with more recent data, we used three additional data sets-the Current Population Surveys, the American Community Survey, and the General Social Survey. Starting in 1994, March Current Population Surveys incorporated several changes that made these surveys much more useful for immigrant research. In particular, questions were added about immigrant status and country of birth of the respondent and parents, and ancestry. While containing much smaller sample sizes than the decennial Census files, these recent CPS innovations make that data much more useful. For this research, we use the 1994 to 2006 CPSs to represent the mid 1990s and early 2000s to describe all three immigrant generations.

The more recent period is derived from the American Community Survey (years 2000- 
2008) and the General Social Survey (years 1994-2006). The American Community Survey identifies the first generation and the second plus generations from an ancestry question. In addition to ancestry, the General Social Survey asks about birth place of self, parents, and grandparents as well as ancestry so that in principal four immigrant generations can be identified.

As indicated by Appendix Table A, the first generation is identified in all data sources and thus all surveys are used to compute education means by European immigrant groups. The second generation only was not identified in either the 1980-2000 decennial Censuses or in the American Community Surveys so those data sources are not used to identify second generation cohort-specific education means.

Third plus generations data are all derived from questions on ancestry. These data are pooled from three distinct sources. The pooled 1994-2006 CPS identify directly the third generation as does the 1994-2006 General Social Surveys, although the latter data set also allows a separation of the third generation from all that followed. Given the relatively small size of these data sets in terms of specific European nationalities identified, we also used the much larger files from the 1980-2000 decennial Censuses and the American Community Surveys 2000-2008 to compute education means by birth cohort by specific European ancestry for the second plus ancestry group. Since we know the means of the second generation and the fraction of the second plus generation who are exactly second generation, we are able to use this data to derive the implicit means of the third plus generations.

Since the third plus generation is derived from answers to questions on ethnicity and heritage rather than country of birth of ancestors, the self assignment to a specific ethnicity depends on the degree of ethnic attribution (Waters and Eschbach, 1995; Smith and Edmonston, 1999). This is especially the case when there exists mixed ancestries in people's backgrounds. 
Country of origin ancestries differ in the extent to which their progeny assign their ancestry to a specific ancestry. A common example that is used is Ireland where rates of ethnic attribution to Ireland tend to be high.

\section{The education of European Immigrants to the United States}

Figure 1 (for men) and Figure 2 (for women) plot for each of our European immigrant groups mean years of education completed arrayed by five-year birth cohorts of immigrants ${ }^{6}$. Before highlighting the major patterns in this data, it is prudent to mention a few sources of bias that may be present in their construction. First, some migrants arrived as young children and their education accomplishments more likely reflect the prevailing school systems in the United States than that in the sending countries. A second source of potential bias we label emigration bias - the selectivity of those migrants to America who subsequently leave the US most likely but not necessarily to return to the sending country. Based on the sparse existing historical literature, characterizing the possible bias due to emigration of previous cohorts is quite complex, especially for the historical periods of interest in this research. For example, for a more recent period, Jasso and Rosenzweig (1990) show that the schooling selectivity bias due to emigration differed significantly between the decades 1960-1970 compared to 1970-1980.

A third source of potential bias is mortality bias. As these immigrant generations become older, survival is most likely related to education so that the mean education of the survivors will exceed the means of the full original cohorts (Kitagawa and Hauser, 1968; Cutler and LlerasMuney, 2010). It is important to note that mortality bias affects all our comparison groups as

\footnotetext{
${ }^{6}$ Several studies have pointed out that education accomplishments using Census data appear to drift upwards over time even when we are well past normal school attendance ages. This educational drift across our data has been attributed to a possible desire to exaggerate one's education as the education norms in society increase and at older ages to education selection in mortality (Smith 1984). Our averaging of the cohort specific data from many sources over time tends to reduce the bias in this effect. This averaging did not distort the main message of this paper.
} 
well—native-born Americans and residents of sending countries so that our comparisons will only be affected by differential mortality bias across these groups. Mortality bias only operates at relatively older ages and the weight of our cohort averages are in the middle ages so mortality bias is unlikely to have a big effect on our cohort means in this paper.

With these caveats in mind, the data presented in Figures 1 and 2 highlight some central facts about European immigrants to the United States in the last two centuries. ${ }^{7}$ Using years of schooling as our index of human capital, even among these European immigrants there exists considerable heterogeneity amongst the main sending countries in the amount of human capital that they brought with them to the United States. For example, among male immigrants born in the 19th century, the average education was highest among the Scottish and English (about 8.5 years of schooling) followed by male German immigrants with about 8 years of schooling on average. Next in line would be Irish and Scandinavian male immigrants with about 7.5 years of schooling on average. The two country groups of European immigrants who distinctly stand apart among those born in the 19th century were the Italians (4 years of schooling) and the Poles (4.5 years of schooling) who had half as much schooling as the English and Scottish.

These across-country patterns by birth cohorts are very similar among female immigrants in Figure 2, with female immigrants having about one-third to one-fifth a year less schooling than their male counterparts. For all countries save Ireland, the strong tendency is for malefemale differences in education to narrow in the $2^{\text {nd }}$ and subsequent generations as the children of immigrants get treated more equally in the schooling. This excess of male education over that of their female counterparts in the first generation is especially high among birth cohort born between 1921and 1940, an indication that education selectivity of male immigrants may have

\footnotetext{
${ }^{7}$ In the Figures in this paper, we always include England in both panels so that there exists a common comparison point for all countries.
} 
been especially high during those years.

To this point, we have characterized the human capital of European immigrant birth cohorts by the use of means. However, there exists considerable heterogeneity in educational accomplishments within these birth cohorts in these European sending countries. To depict this heterogeneity, Tables 2.A (for men) and 2.B (for women) presents $10^{\text {th }}, 25^{\text {th }}, 50^{\text {th }}, 75^{\text {th }}$, and $90^{\text {th }}$ percentiles of the education distributions. For these tables, we divided the birth cohorts into three groups - those born in the $19^{\text {th }}$ century (1860-1900), those born in the first half of the $20^{\text {th }}$ century (1901-1950), and those born in the second half of the $20^{\text {th }}$ century (1951-1985).

Not only do these European sending countries differ in the average education of immigrants to the United States, if anything the differences within country in education of immigrants, especially in the $19^{\text {th }}$ century, are even larger. In all sending countries, the amount of years of schooling at the $90^{\text {th }}$ percentile is at least three times that at the $10^{\text {th }}$ percentile. Large fractions of Italian and Polish immigrants of both genders immigrated to the United States with no schooling at all. For example, more than $25 \%$ of Italian and Polish female immigrants in the $19^{\text {th }}$ century had zero years of schooling. Over time, however, not only did the average levels of schooling of European immigrants to the United States increase significantly, there was an even larger fall in the dispersion of education outcomes among immigrants birth cohorts in all these countries in the $20^{\text {th }}$ century. To illustrate, in Table 2.A the increase over time in Irish male immigrant education was 8 years at the $10^{\text {th }}$ percentile compared to 5 years at the $90^{\text {th }}$ percentile. For Polish male immigrants the comparable numbers were 11.5 years at the $10^{\text {th }}$ percentile compared to 7 years at the $90^{\text {th }}$ percentile. A similar reduction in dispersion within birth cohort and within country also characterizes the patterns for female immigrants. We conjecture that very often the $10^{\text {th }}$ and $25^{\text {th }}$ percentiles of the education distribution contributed to the negative 
stereotypes of many of these immigrant groups, in particular the Irish, Italians, and Poles.

\section{The Education of the Descendants of Immigrants}

\subsection{Conceptual Approach}

In this section, we explain our methodology for computing the progress in education attainment for the children and grandchildren of European immigrants that can be attributed to the decision to immigrate to the United States. We illustrate our methodology using the case of Italian male immigrants to the United States in Table 3. All the education data in Table 3 are arrayed by five year birth cohorts of Italian male immigrants. The column labeled 'first' lists the mean education of Italian male immigrants themselves, data that were already displayed graphically in Figure 1.

In Table 3, mean education completed is also listed for the second generation (the male American-born children of these Italian male immigrants) and the third plus generation (the American-born grandchildren plus of these Italian immigrants). To highlight generational

progress, $2^{\text {nd }}$ and $3^{\text {rd }}$ generation education data are arrayed not by their own cohort birth years, but rather by the birth cohort years of their immigrant Italian fathers ( $2^{\text {nd }}$ generation) or grandfathers ( $3^{\text {rd }}$ plus generations).

We assume in these computations a 25 year generational lag. To illustrate, Italian male immigrants to America who were born in 1901 to 1905 completed 6.52 years of schooling. Their male sons born 25 years later between 1926- 1930 completed 12.12 years of schooling-a generational schooling advance of 5.60 years. Their Italian ancestry grandsons born on average another 25 years later between 1936-1940 achieved 13.9 years of education, a smaller (1.8 years education gain) but still a significant sign of continuing educational progress across Italian 
immigrant generations. From the first to the third generation, the increase in average education was a very impressive 7.38 years. ${ }^{8}$ The difference between the education of children and/or grandchildren of migrants and the immigrants themselves we label 'gain if migrate.'

However, this is not the conceptually correct measure of the generational gain in education from immigration since it has the wrong counterfactual—no education gain to the children and grandchildren of immigrants if the immigrants had remained in the sending countries. But in many of these European countries education levels were rising quickly during this time period so that the children and grandchildren of migrants would certainly have had more education than their parents and/or grandparents even if their immigrant ancestors had remained in the sending countries.

The difficulty in quantifying within-country education advances is that collection of population representative education data in European countries lagged decades beyond that of what is available in the United States through the decennial American Censuses. An alternative method is suggested by the 'first' column in Table 3 which displays education levels of future Italian male migrant birth cohorts to the United States. If migrants tend to be positively selected on their schooling, the average migrant will have more education than the average of the sending country birth cohort of which he/she was a part. If we adopt for the moment the time neutral assumption that migrant selection in education remained constant over time, then the mean education of migrants who were born 25 years later would represent the mean education of migrants’ children if the migrants had not left.

To illustrate once again using Table 3, male children of Italian male migrants who were

\footnotetext{
${ }^{8}$ Since we are assuming a 25 year generational lag, education by generation numbers for the non-first generation immigrant generations probably understate mean education of the average same gender children and grandchildren since the average age distance between the generations will typically be larger than 25 years. The generational numbers should be thought of as generational differences of the first American-born child of the immigrants
} 
born between 1901 and 1905 were themselves born between 1926-1930 and, using the constant migrant education selectivity assumption, would have had 9.32 years of schooling. The difference between this mean years of schooling and that of the immigrant fathers 25 years before we label the 'gain if stay' which in this case is 2.80 years of schooling. Finally, for the second generation the difference between the 'gain if migrate' (5.60) and the 'gain if stay' (2.80) is the conceptually correct measure of the education gain to the second generation from the migration decision of these Italian migrants born between 1901-1906. We label that difference 'diff' and in this case the 'diff' is $5.60-2.80$ or 2.8 years of schooling. Thus, immigration led to a doubling of the education gains between the first and second generation for this Italian immigrant birth cohort.

We can perform the same type of computation between the second and third generation or between the first and third generation. Using the Italian males in Table 3 to illustrate, the American-born grandsons of Italian migrant born between 1901-1906 had 7.38 more years of schooling than their migrant grandfathers. If their grandfathers had stayed in Italy, the grandsons would have had 5.99 years of schooling than their grandfathers so that the education gains between the first and third generation is 1.39 years of schooling.

This conceptual framework we have just discussed for Italian male immigrants is used in this paper to compute the 'gain if migrate,' 'gain if stay,' and 'diff' in all our European countries for male and female immigrants alike. We present these results in the next section. We then relax the assumption of constant education migrant selection in Section 5 below.

\subsection{Education Advances across European Immigrant Generations and Countries}

In this section, we generalized the conceptual approach outlined in the previous section to 
compute the 'gain if migrant', ' gain if stay' and 'diff' for all our European countries. We do this not only for education advances of the American born children of these European migrants, but also the grandchildren of these migrants- ie- education gains between the first and third plus generations.

\subsubsection{The Second Generation}

Figures 3-5 contrast the education consequences for the second generation children of European immigrants of their parents' decision to migrate to the United States. Once again the 'gain if migrate' concept in Figure 3.A (for men) and Figure 3.B (for women) represents the mean education of children of immigrants minus the education of the migrants themselves, all arrayed by birth year cohorts of immigrants. This measures second generation education increments over that of the first generation.

Similarly, Figure 4.A (men) and 4.B (women) plot the 'gain if stay'—the hypothetical generational education improvement if these migrants had remained in their respective sending counties. The education increment if migrants had stayed in the sending country is equal to the mean generational improvement in schooling in the sending countries adjusted for any alteration in the degree of migrant selection in schooling over time. In constructing these figures, as explained above, we maintain the constant migration education selection assumption. Finally under constant education selection, the true education gains from the decision to migrate to the second generation - 'diff' — is the difference between 'gain if migrate' and 'gain if stay' and are displayed in Figures 5.A and 5.B.

Figure 3 shows significant advances in schooling between the first and second generation for all these European sending countries for men and women alike. If we examine patterns across the European countries, the largest generational improvements in schooling occurred in countries 
with the biggest initial immigrant schooling gaps with Native-born Americans (Italy and Poland). Among immigrants born in the $19^{\text {th }}$ century in Italy and Poland, the education gain of the second generation often exceeded five years. Next in line in terms of the 'gain to migrate' measure come the Scandinavian countries, followed closely by the Scots and the Irish, In contrast, we document relatively small $1^{\text {st }}-2^{\text {nd }}$ generation schooling advances for English and German migrants. Over the course of the $20^{\text {th }}$ century, the excess of the education of the second generation compared to the first—-gain to migrate’—apparently became progressively smaller. This may not be surprising as all these European immigrant groups converge over these birth cohorts to the same set of education norms.

Figure 4 labeled 'gain if stay' measures the hypothetical generational education improvement if migrants had remained in their respective sending counties. The 'gain if stay' is basically capturing (under the constant migration education selectivity assumption) how rapidly schooling levels were advancing over time in these sending countries.

Figure 4 documents a significant and steady increase in education levels over time with very large gains in the first decades of the 20th century that were typically twice as large as in the 19th century. The early decades of the $20^{\text {th }}$ century in particular were years of impressive education advances over time in Western Europe. Over the twenty five year generational period in which we measure the 'gain to stay' peaked at about five years in Poland and around 3 years in the other sending countries with Italy a bit above the others. It is well documented that the early decades of the 20th century was a period of significant cohort advances in schooling, a pattern that is replicated in our 'gain to stay' graphs.

These across cohort improvements within Western Europe then diminished for birth cohorts as we move through the 20th century until they are about zero among the most recent 
birth cohorts depicted in these graphs. The typical pattern for the size of these education advances is to slowly attenuate over the remaining decades of the $20^{\text {th }}$ century as Western Europe achieved its goal of becoming a highly educated set of countries. Most important, the size of these 'gains to stay' implies that we cannot ignore them in computing the education gains attributable to the European experience of migrating to the United States.

Figure 5 differences the 'gain to migrate' and 'gain to stay' concepts to produce the 'diff' plots - the amount of education improvement of the second generation that can be attributed under constant education selectivity to the decision to migrate to the United States. The improvements over time in schooling levels in most of these European sending countries were sufficiently large that the education gains of the children of European migrants in the United States were not that much higher than those that would have occurred in the sending countries anyway. In fact for England and Germany and for the latter decades of the $20^{\text {th }}$ century the Scandinavian countries, the decision to migrate to the US actually lead to a small net loss in their children's education compared to what would have taken place if the migrants had instead remained at home.

The major exception to this portrait of relatively small gains or even small losses to the $2^{\text {nd }}$ generation's education due to the migration decision are the Italians and to a lesser extent the Poles. Earlier Italian migrants stand apart with net education gains of the American born children of Italian migrants reaching almost four years for those born between 1906-1910 after which their 'diff' steadily declines while remaining positive throughout the remaining Italian birth cohorts of the $20^{\text {th }}$ century.

\subsubsection{The Third Generation}

The same conceptual issues just applied to the second generation apply as well to the 
grandchildren of immigrants and subsequent generations. In this sub-section, we extend our framework using the same three conceptual concepts—-'gain if migrate,' 'gain to stay,' and 'diff' to examine the consequences of immigration for the grandchildren plus. Using the same format as in the previous section for the children of immigrants, Figure 6 plots the 'gain if migrate' and Figure 7 the 'diff' for the education advances between the immigrant generation and the third generation plus for both men and women. Once again, all birth years are indexed by the year of birth of the immigrant generation so that the education of the third plus generation refers to those born fifty years of more after the immigrants.

The heterogeneity amongst European sending countries is much smaller for education advances between the second and third generation than it was for first to second generation comparisons. With the exception of Poland, education increments between the second to third generation range from 2.5 to 3 years of schooling in these European countries for those whose immigrant grandparents were born in the latter decades of the $19^{\text {th }}$ century. The $2^{\text {nd }}$ to $3^{\text {rd }}$ plus generation schooling advances for Polish heritage people average about a year more. As was the case for $1^{\text {st }}$ to $2^{\text {nd }}$ generation education improvements, for these European countries the size of the education increments between the $2^{\text {nd }}$ and $3^{\text {rd }}$ generation steadily declines among more recent birth cohorts of migrants. After the $2^{\text {nd }}$ generation the ethnic origin of the immigrant progeny apparently begins to matter less and their education progression across generations becomes very similar.

Figure 6 combines the education gains between the first three generations for the 'gain if migrate' concept between the $1^{\text {st }}$ and $3^{\text {rd }}$ plus generations. Across three generations, Poland and Italy lead the pack with education advances of almost 8 years as the descendants of Polish immigrants made up a slight deficit compared to the Italians between the $1^{\text {st }}$ and $2^{\text {nd }}$ generation 
with the largest increment between the $2^{\text {nd }}$ and $3^{\text {rd }}$ plus generation. Most of the other European countries achieved three generation education gains between four and six years with all these education advances becoming smaller among recent cohorts.

As we have established, the $3^{\text {rd }}$ generational progeny of immigrants would have enjoyed improvements in their education accomplishments even if their grandparents had remained in Europe. For each birth cohort of immigrants, the relevant 'gain if stay' is the fifty year improvement over time in the sending country. Subtracting the 'gain if stay' from the 'gain if stay' gives us the three generation 'diff' which are displayed in Figure 7. Figure 7 illustrates quite dramatically that the principal European sending country for which the decision to migrate lead to large improvements in the education of their grandchildren was Italy and to a lesser extent Poland for women in the $19^{\text {th }}$ century. For many of the other prominent European countries the idea that there were large education advances for the grandchildren of migrants that would not have taken place is largely a myth,

While they lagged in timing behind the United States, this is essentially due to the fact that in the 20th century this set of European countries also witnessed significant improvements over time in years of schooling completed for which the children and grandchildren of migrants would also have been beneficiaries. In fact, these education advances across cohorts were sufficiently large in England, Germany, and Scotland that we consistently compute a negative diff for those countries implying that on average education of children of migrants in these countries would have been slightly higher if the migrants stayed in the sending country. This does not imply that these migrants did not gain from their migration to America—only that part of the gain was not education improvements for their children in the quantity of schooling they would achieve. 


\section{Relaxing the Constant Education Selectivity Assumption}

The assumption of constant immigrant education selection was invoked in the previous sections due to the absence of long-term time series data on education levels in European countries that could be compared to the education accomplishments of European immigrants and their descendants in the United States. National population representative data on years of education completed has a much longer history in the United States than it does in many European countries. In the United States, Census data on education goes back as far as the 1940 Census while most European countries did not collect population representative survey data on years of schooling completed especially on a comparable basis until much later. Thus, we are unable to describe education trends in European sending countries in the 19th and the early decades of the 20th century and thus directly take into account changing degrees of education selectivity of immigrants during that time period.

The education increment if migrants had stayed in the sending country is equal to the mean generational improvement in schooling in the sending countries adjusted for any alteration in the degree of migrant selection in schooling over time. In this section, we present two approaches that provide insight into possible trends in the extent of changing education selectivity of immigrants. The first approach outlines a basic economic model of migration selection that highlights the role that more observable factors, such as migration costs and income differences between countries, play in the changing selectivity of migrants to the United States. The second approach uses actual education data in the European sending countries to measure education selection for a more limited set of post 1920 birth cohorts of immigrants.

\subsection{Long Term Model of Migration Selection}


We simplify our migration model by assuming that individuals consume all their income so that the decision to migrate becomes a simple single period income maximization model on an income choice between living in the home county $\mathrm{H}$ and an away country A. Income is the product of i's human capital $(\mathrm{k})$ and the relative location-specific wage rates for a unit of human capital (w). An individual will migrate if the income difference between the away country and sending country exceeds the cost of migration $\theta_{i}$ That is,

(i) $\quad w_{A} k_{t A}-w_{H} k_{t H}>\theta_{t} \quad \theta_{t}=$ cost of migration

Cross-country wage rate are related by the following equation

(ii) $w_{A}=\beta_{0}+\beta_{1} w_{H E} \quad \beta_{0}>0 ; \beta_{1}>1$

To justify economic migration typically $\beta_{0}$ will be positive. $\beta_{1}$ measure a relative skill price premium between home and away country. If wages of skilled labor are relatively high in a receiving country, $\beta_{1}>1$. Assuming that human capital is completely transferable across countries we can solve for human capital (in our case implicitly education) as

(iii) $\quad k_{t}\left(\beta_{0}+w_{H}(\beta-1)\right)>\theta_{t}$

Equation (iii) provides us with several insights into selection mechanisms which can influence migration flows. First, higher migration costs $\theta_{i}$ will require higher levels of human capital $k_{i}$ to justify migration. Therefore when the costs of migration are high, migrants should be more positively selected on education.

Unless migration costs are negative ${ }^{9}$, any parameter lowering the size of the term in parenthesis is equation (iii) implies that migrants must be more skilled (i.e., educated) to justify migration since it will take more skilled migrants to offset migration costs. Thus, the lower the uniform wage premium $\left(\beta_{0}\right)$ of receiving to sending country, the more skilled or educated

\footnotetext{
${ }^{9}$ For a case when migration costs are negative, see Delaney and Smith (2013)
} 
migrants will be relative to the average skill and education in the sending country. As incomes of the European sending countries converge toward those in the United States, migrants should be more positively selected on education. Finally, the greater the wage skill premium $\left(\beta_{1}\right)$ in the receiving country relative to sending country will lower the extent of education of migrants.

\subsection{Income Data by Country over Time}

This economic model of migration has two simple predications. First, as the costs of migration between two countries rises (falls), the human capital (education) of migrations will rise (fall) making migrants more (less) selective in education. In the 19th century in an era of unrestricted migration the costs of migration (transportation costs) probably slowly fell over time producing a slow decline in the education selectivity of migrants. Similarly, the growth of ethnic enclaves from previous migrants from the same country probably produced the same slowly evolving effect of declining migration costs over time as the costs of assimilation into a new country fell. Second, as income differences between two countries narrow, the education selection of migrants will rise making migrants more selective in education.

To assess the importance of the latter factor, we need data on long-term income differences between our European sending countries and the United States. Our country GDP per capita was derived from the Madison Historical GDP data-set (measured in 1990 Geary-Khamis dollars). The data are relatively complete for many of our European countries (the $\mathrm{UK}^{10}$, Italy, Sweden, and Germany) from 1870 onwards. Data for Ireland are not constructed separately until 1921 when Ireland became independent from the UK and for Poland beginning in 1930. We express all country incomes over time relative to the United States in the same year.

Our plots of these relative income series are contained in Figures 8.A (for the longer time series available for the UK, Italy, Sweden, and Germany) and in 8.B (for the post 1920 years

\footnotetext{
${ }^{10}$ This series does not provide separate data for England and Scotland.
} 
adding Ireland and Poland to the original four countries). In the last half of the 19th century, these European countries are clearly ranked. The UK is by far the highest even exceeding income per capita in the United States during the latter half of the $19^{\text {th }}$ Century. Next in line comes Germany where income per capita was consistently about $70-80 \%$ of that observed in the US. For most of the last half of the 19th century levels of GDP per capita incomes in Italy and Sweden were about half those in the United States.

Figure 8.B traces out the relative income series for a larger set of our countries for which we have data in the 20th century. Of all our European countries in the pre-World War 2 years, relative incomes were lowest in Poland with incomes in Ireland on a par with those in Italy. Trends in the 20th century are clearly distorted somewhat by the large drop in relative incomes (compared to the United States) during the great depression and the second World War and subsequent recovery in all our European countries immediately after World War 2.

A clearer picture of long term trends emerges if those years are eliminated from the graph which is done in Figures 9.A and 9.B. Not surprisingly, relative incomes are highest in Sweden, the UK, and Germany with no sharp time series trends for those countries in the post WW2 period with incomes around $75 \%$ of those in the US. In contrast, relative incomes in Italy and especially in Ireland during the period of the Celtic Tiger period were clearly improving steadily throughout the post WW2 period in these graphs. We find little change in relative incomes during this time period in Poland which remained below $40 \%$ of levels in the United States.

What are the implications of these between country income trends for the education selectivity of European migrants? First, among those potential migrants born in the 19th century in the era of unrestricted European migration to the United States, migration costs were probably declining slowly for the reasons outlined above implying as well a slow decline in the education 
selection of European migrants in the $19^{\text {th }}$ century. Secondly, with the exception of the UK where incomes relative to the US were clearly declining (implying less education selection), income gaps of other European countries relative to the US do not indicate sharp trends in the latter half of the $19^{\text {th }}$ century. This income data would suggest that there are not compelling reasons with the exception of the UK for the education selectivity of European migrants to change that much in the $19^{\text {th }}$ century.

In the $20^{\text {th }}$ century, income gaps between Europe and the US were also relatively stable with the obvious exception of Italy and Ireland where in the second part of 20th century, relative incomes of Italy and especially Ireland rose dramatically relative to the US. Our theory outlined above would suggest constant education selection for the other countries and rising education selection in Italy and Ireland. As we shall see in the next section, this did not occur due to another change in immigration law in the United States.

\subsection{Mid-20 ${ }^{\text {th }}$ Century Trends in Education Selection of European Migrants to the United States}

To assess, at least for most of the 20th century, education selectivity trends in our sending European countries on a comparable basis, we use five waves of the European Social Survey, conducted between 2002 and 2010. In these surveys, respondents were asked, in the context of a large social and political attitudes survey, to report their number of years of education and their year of birth. Since number of years of schooling attended will normally exceed number of years of schooling completed (which is our definition in the American data), in terms of a comparison with the American data on education presented above the European data will most likely slightly overstate the education accomplishments in the European sending countries. However, and much more importantly for our purposes, the European and American data are both consistently 
defined across birth cohorts and surveys so that the respective across cohort trends for each series does not contain an obvious source of bias.

With this data, we are able to describe within each European country trends in years of education attended for birth cohorts living in those countries starting with those born between 1921-1925. Such trends of course suffer from the same sorts of biases that are contained in the American data including mortality bias, emigration bias, and exaggeration bias over time.

To obtain an index our education selectivity of these European migrants, for each birth cohort and gender we then subtract from the mean education of European migrants to the United States the mean level of education of those who remained in the sending country. The resulting measures of education selection of European migrants are listed for each European sending country and for men and women separately in Table 4.

The general trend is clear-in most countries across this time period initially European immigrants to the United States were quite positively selected in terms of education. Since the largest amount of positive education selection in migrants characterized the earliest birth cohorts in Table 4 for most countries and our examination of trends in migration costs and between country income differences between Europe and the United States indicated relative stability in the $19^{\text {th }}$ century ${ }^{11}$ with declining migration costs over time looking backwards this would suggest that for the mid-19 $9^{\text {th }}$ century onward to 1921-1925 European migrants might have been even slightly more positively selected in terms of education.

However, especially for those born after 1940 the positive education selection in European migrants clearly attenuated so that by the end of the time period examined in Table 4 the positive selection by education of European immigrants to the United States was quite small especially compared to prior historical norms. If we only thought of these migrants as economic

\footnotetext{
${ }^{11}$ Once again, the UK is the obvious exception .
} 
migrants for whom the theory above applies that would actually be a bit of a puzzle since if anything income gaps between Western Europe and the United States narrowed somewhat implying more positive selection.

The reasons for this sharp decline in education selection in Table 4 in our view no doubt rest in the changing criteria for legal admission to the United States over this time period. Over this time period, international European migrants became not only severely supply restricted by country specific quotas, but they were admitted to the United States largely (75\%) on family related visas (spouses, siblings, parents) rather than on employment related visas where one might suspect that education selection would be much strongest.

In addition, this declining levels of education selection in the $20^{\text {th }}$ century documented in Table 4 implies that we are if anything understating the 'gains to stay' during this period which means we overstating 'diff' so our conclusions that the children and grandchildren of European migrants did not gain significantly in terms of education by the decision of the parents or grandparents to migrate to the United States remains valid.

\section{Conclusions}

In this paper, we investigate the human capital (education) gains of descendants of immigrants from the principal European sending countries to the United States. Our perspective is decidedly long term since we examine birth cohorts of European immigrants born in the last half of the $19^{\text {th }}$ century and through most of the $20^{\text {th }}$ century. Over the time period we cover, the majority of immigrants to the United States were Europeans.

We develop in this paper a more conceptually appropriate measure of generational gains in education from international migration by taking into account not only what happened to the education of descendants of immigrants in the United States but also what was most likely to 
have happened to their education if their immigrant parents and grandparents had instead remained in the sending countries. Measuring Human Capital gains through international migration across generations requires knowing what was happening in sending and receiving countries.

There exists considerable heterogeneity within specific countries over time and across these European countries in the education benefits to the descendants of European immigrants to the United States. In the European context, these education gains to descendants of immigrants are particularly large among Polish and Italian migrants who came from sending countries characterized by very low educational accomplishments. As education levels in these European sending countries improved over time, the size of the generational education gains attributable to immigration steadily declined. 


\section{References}

Cutler, David M. and Adriana Lleras-Muney (2010). "Understanding Health Differences by Education,” Journal of Health Economics, Volume 29, Issue 1, January 2010, Pages 1-28.

Delaney, Liam and James P. Smith (2013). "Exporting Poor Health? the Irish in the UK”. Demography. December 2013

European Social Surveys: Waves 1 - 5. Last downloaded May 2nd 2013 at http://ess.nsd.uib.no/

Jasso, Guillermina and Mark R. Rosenzweig. 1990. The New Chosen People: Immigrants in the United States. New York: Russell Sage Foundation.

Kesternich Iris, Bettina Siflinger, James P Smith and Joachim Winter "The Effects of World War II on Economic and Health Outcomes across Europe.” December 2011. The Review of Economics and Statistics, forthcoming.

Kitagawa, Evelyn M. and Philip M. Hauser (1968). "Educational Differentials in Mortality by Cause of Death: United States, 1960.” Demography 5(1): 318-353.

Madison Historical GDP Data http://www.worldeconomics.com/Data/MadisonHistoricalGDP/Madison\%20Historical\%20 GDP\%20Data.efp

Bolt, J. and J. L. van Zanden (2013). The First Update of the Maddison Project; Re-Estimating Growth Before 1820. Maddison Project Working Paper 4.

Passel, Jeff S, “Emigration—Measurement issues and new estimates,” in Proceedings of the conference on Congress and Tomorrow's Foreign-Born Population: Evaluating Immigration Projections, sponsored by the Institute for the Study of International Migration, Washington, DC, USA, September 2006.

Smith, James P. “Race and Human Capital,” American Economic Review 74(4):685-698, September 1984.

Smith, James P. and Barry Edmonson. The New Americans: The Economic, Demographic, and Fiscal Consequences of Immigration, National Academy Press, October 1997.

Smith, James P. “Assimilation across the Latino Generations,” American Economic Review 93(2):315-319, May 2003.

Smith, James P. "Immigrants and the Labor Market,” Journal of Labor Economics 24(2):203233, April 2006 
Waters, Mary. C and K. Eschbach. 1990. Immigration and ethnic and racial inequality in the United States. Annual Review of Sociology 21 419-446. 
Table 1. European Immigrants Flows into the United States by time and selected countries

\begin{tabular}{|c|c|c|c|c|c|c|c|c|c|c|}
\hline Time period & $\begin{array}{l}\text { Total } \\
(000)\end{array}$ & $\begin{array}{c}\% \\
\text { European }\end{array}$ & UK & Irish & Germans & Scandinavian & Italians & Polish & $\begin{array}{l}\text { All six as \% of } \\
\text { total European }\end{array}$ & Soviet Union \\
\hline $1851-1870$ & 4,913 & 92.0 & 22.8 & 29.9 & 38.5 & 3.3 & 0.05 & 0.01 & 95.1 & 0.0 \\
\hline $1871-1890$ & 8,058 & 87.0 & 19.3 & 15.6 & 31.0 & 14.1 & 5.2 & 0.1 & 85.0 & 3.6 \\
\hline $1891-1910$ & 12,483 & 93.6 & 6.8 & 6.2 & 7.2 & 7.5 & 23.1 & 0.1 & 50.9 & 18.0 \\
\hline $1911-1930$ & 9,843 & 68.9 & 10.0 & 5.3 & 12.5 & 12.9 & 23.0 & 1.4 & 65.1 & 14.5 \\
\hline $1931-1950$ & 1,563 & 61.9 & 17.7 & 3.2 & 35.2 & 3.8 & 13.0 & 2.6 & 75.5 & 1.9 \\
\hline $1951-1970$ & 5,836 & 42.3 & 16.9 & 3.3 & 27.1 & 1.6 & 16.2 & 2.6 & 67.7 & 2.1 \\
\hline $1971-1990$ & 11,831 & 12.7 & 17.7 & 3.1 & 9.0 & NA & 10.8 & 9.4 & 50.0 & 8.4 \\
\hline
\end{tabular}

Source: Historical Statistics of the United States. 
Table 2.A

Education Percentiles by Country and Time Period-Male Immigrants

\begin{tabular}{|c|c|c|c|c|c|}
\hline Percentile & p10 & p25 & p50 & p75 & p90 \\
\hline & \multicolumn{5}{|c|}{ Irish } \\
\hline $1860-1900$ & 4 & 6 & 8 & 8 & 12 \\
\hline $1901-1950$ & 7 & 9 & 12 & 13 & 17 \\
\hline 1951-1985 & \multicolumn{5}{|c|}{ Scottish } \\
\hline $1860-1900$ & 6 & 8 & 8 & 12 & 13 \\
\hline 1901-1950 & 8 & 11.5 & 12 & 15 & 17 \\
\hline 1951-1985 & 12 & 12.5 & $\begin{array}{l}15 \\
\text { Po }\end{array}$ & 16 & 17 \\
\hline $1860-1900$ & 0 & 2 & 5 & 8 & 10 \\
\hline 1901-1950 & 6 & 8 & 12 & 14 & 17 \\
\hline 1951-1985 & \multicolumn{5}{|c|}{ English } \\
\hline $\begin{array}{l}1860-1900 \\
1901-1950\end{array}$ & $\begin{array}{l}5 \\
9\end{array}$ & $\begin{array}{c}7 \\
12\end{array}$ & $\begin{array}{c}8 \\
13\end{array}$ & $\begin{array}{l}12 \\
16\end{array}$ & $\begin{array}{l}14 \\
18\end{array}$ \\
\hline $1951-1985$ & 12 & \multicolumn{3}{|c|}{ German } & 17 \\
\hline $1860-1900$ & 4 & 7 & 8 & 10 & 12 \\
\hline 1901-1950 & 8 & 11.5 & 12.5 & 16 & 17 \\
\hline 1951-1985 & \multicolumn{5}{|c|}{ Scandinavian } \\
\hline $1860-1900$ & 4 & 7 & 8 & 8 & 12 \\
\hline 1901-1950 & 7 & 8 & 12 & 15 & 17 \\
\hline 1951-1985 & 12 & 13 & $\begin{array}{l}16 \\
\text { Ita }\end{array}$ & 17 & 17 \\
\hline $1860-1900$ & 0 & 2 & 4 & 8 & 9 \\
\hline 1901-1950 & 4 & 6 & 9 & 12 & 15 \\
\hline 1951-1985 & 10 & 12 & 13 & 16 & 17 \\
\hline
\end{tabular}


Table 2.B

Education Percentiles by Country and Time Period-Female Immigrants

\begin{tabular}{|c|c|c|c|c|c|}
\hline Percentile & p10 & p25 & p50 & p75 & p90 \\
\hline & \multicolumn{5}{|c|}{ Irish } \\
\hline $1860-1900$ & 4 & 6 & 8 & 8 & 12 \\
\hline 1901-1950 & 7 & 9 & 12 & 12.5 & 15 \\
\hline 1951-1985 & \multicolumn{5}{|c|}{ Scottish } \\
\hline $1860-1900$ & 6 & 8 & 8 & 12 & 12 \\
\hline 1901-1950 & 8 & 11.5 & 12 & 13 & 15 \\
\hline 1951-1985 & 12 & 12 & $\begin{array}{r}13 \\
\mathrm{Po}\end{array}$ & 16 & 17 \\
\hline $1860-1900$ & 0 & 0 & 4 & 8 & 8 \\
\hline 1901-1950 & 5 & 7 & 12 & 12 & 16 \\
\hline 1951-1985 & \multicolumn{5}{|c|}{ English } \\
\hline $1860-1900$ & 5 & 7 & 8 & 12 & 12 \\
\hline 1901-1950 & 9 & 12 & 12 & 13 & 16 \\
\hline 1951-1985 & 12 & 12 & $\begin{array}{l}13 \\
\text { Gel }\end{array}$ & 16 & 17 \\
\hline $1860-1900$ & 4 & 7 & 8 & 9 & 12 \\
\hline 1901-1950 & 8 & 11.5 & 12 & 13 & 16 \\
\hline 1951-1985 & \multicolumn{5}{|c|}{ Scandinavian } \\
\hline $1860-1900$ & 4 & 7 & 8 & 8 & 12 \\
\hline 1901-1950 & 7 & 10 & 12 & 14 & 16 \\
\hline 1951-1985 & 12 & \multicolumn{3}{|c|}{ Italian } & 17 \\
\hline $1860-1900$ & 0 & 0 & 4 & 7 & 8 \\
\hline 1901-1950 & 2 & 5 & 8 & 12 & 13 \\
\hline 1951-1985 & 10 & 12 & 12.5 & 16 & 17 \\
\hline
\end{tabular}


Table 3: Education by Migrant Generation by Birth Year of Migrants-Italian Males

\begin{tabular}{|c|c|c|c|}
\hline $\begin{array}{r}\text { Year of } \\
\text { Immigrant Birth }\end{array}$ & First & Second & Third \\
\hline 1861-1865 & 3.47 & 7.35 & 9.69 \\
\hline $1866-1870$ & 3.48 & 7.63 & 10.75 \\
\hline 1871-1875 & 3.85 & 8.17 & 11.44 \\
\hline $1876-1880$ & 3.72 & 8.68 & 11.84 \\
\hline 1881-1885 & 4.03 & 9.33 & 12.33 \\
\hline $1886-1890$ & 4.25 & 10.01 & 12.80 \\
\hline 1891-1895 & 4.76 & 10.93 & 13.41 \\
\hline $1896-1900$ & 5.52 & 11.66 & 13.98 \\
\hline 1901-1905 & $6.52(5.60)$ & 12.121 & $13.90(7.38)$ \\
\hline $1906-1910$ & 7.55 & 12.76 & 13.80 \\
\hline 1911-1915 & 1288.06 & 13.21 & 13.79 \\
\hline $1916-1920$ & 8.86 & 13.65 & 14.07 \\
\hline 1921-1925 & 9.58 & 14.11 & 14.03 \\
\hline $1926-1930$ & 9.32 & 13.97 & 14.10 \\
\hline 1931-1935 & 9.05 & 13.83 & 13.96 \\
\hline $1936-1940$ & 9.63 & 13.80 & \\
\hline 1941-1945 & 10.62 & 14.07 & \\
\hline $1946-1950$ & 12.21 & 14.02 & \\
\hline 1951-1955 & 12.51 & 14.09 & \\
\hline $1956-1960 \quad(5.99)$ & 13.18 & 13.96 & \\
\hline
\end{tabular}

Education gains due to migration = gain if migrate - gain if stay.

$2^{\text {nd }}-1^{\text {st }}=(5.60-2.80)=2.60$

$3^{\text {rd }}-1^{\text {st }}=(7.38-5.99)=1.39$ 
Table 4-Education Selectivity by Birth Cohorts in European Sending Countries-Diff between Immigrant and Stayer Education

\begin{tabular}{|c|c|c|c|c|c|c|c|c|c|c|c|c|}
\hline \multirow[b]{2}{*}{ Birth Year } & \multicolumn{2}{|c|}{ England } & \multicolumn{2}{|c|}{ Ireland } & \multicolumn{2}{|c|}{ Germany } & \multicolumn{2}{|c|}{ Italy } & \multicolumn{2}{|c|}{ Poland } & \multicolumn{2}{|c|}{ Scandinavia } \\
\hline & Men & Women & Men & Women & Men & Women & Men & Women & Men & Women & Men & Women \\
\hline 1921-1925 & 2.58 & 1.16 & 0.90 & 1.22 & 0.95 & 1.90 & 1.45 & 3.61 & 2.59 & 2.76 & 3.10 & 2.95 \\
\hline 1926-1930 & 2.57 & 1.36 & 1.07 & 0.68 & 1.12 & 1.67 & 1.99 & 1.66 & 1.87 & 2.81 & 2.73 & 3.63 \\
\hline 1931-1935 & 2.20 & 1.30 & 1.83 & 1.08 & 1.00 & 1.49 & 0.53 & 0.31 & 2.78 & 2.30 & 3.21 & 3.15 \\
\hline 1936-1940 & 2.16 & 1.00 & 1.06 & 0.68 & 0.82 & 1.08 & 1.09 & 0.59 & 2.50 & 2.70 & 2.74 & 2.76 \\
\hline 1941-1945 & 2.35 & 0.76 & 1.29 & 0.75 & 0.60 & 0.87 & 0.72 & 1.18 & 2.56 & 2.51 & 2.62 & 2.25 \\
\hline 1946-1950 & 1.71 & 0.57 & 2.15 & 0.99 & 0.59 & 0.90 & 2.00 & 1.88 & 2.35 & 2.60 & 2.46 & 1.56 \\
\hline 1951-1955 & 0.95 & 0.94 & 1.69 & 0.69 & 0.20 & 0.36 & 0.27 & 2.10 & 2.06 & 1.77 & 1.85 & 0.88 \\
\hline $1956-1960$ & 0.39 & 1.35 & 0.82 & 0.56 & 0.06 & 0.36 & 1.81 & 1.70 & 1.54 & 1.04 & 1.62 & 0.41 \\
\hline 1961-1965 & 0.55 & 0.29 & 0.35 & 0.20 & -0.25 & 0.02 & 1.75 & 1.51 & 1.03 & 0.88 & 1.49 & 0.47 \\
\hline 1966- 1970 & 0.96 & 0.62 & 0.52 & -0.18 & 0.20 & 0.22 & 1.15 & 2.29 & 0.77 & 0.73 & 1.54 & 0.24 \\
\hline 1971-1975 & 0.37 & 0.16 & -0.25 & 0.02 & -0.28 & 0.31 & 0.92 & 1.56 & 0.41 & 0.34 & 0.81 & -0.04 \\
\hline $1976-1980$ & 0.04 & 0.71 & -0.75 & -0.20 & 0.98 & 0.15 & 0.99 & 1.08 & 0.51 & 0.50 & 0.74 & 0.25 \\
\hline
\end{tabular}


Figure 1. Education by Immigrant Generation by Year of Birth-Males
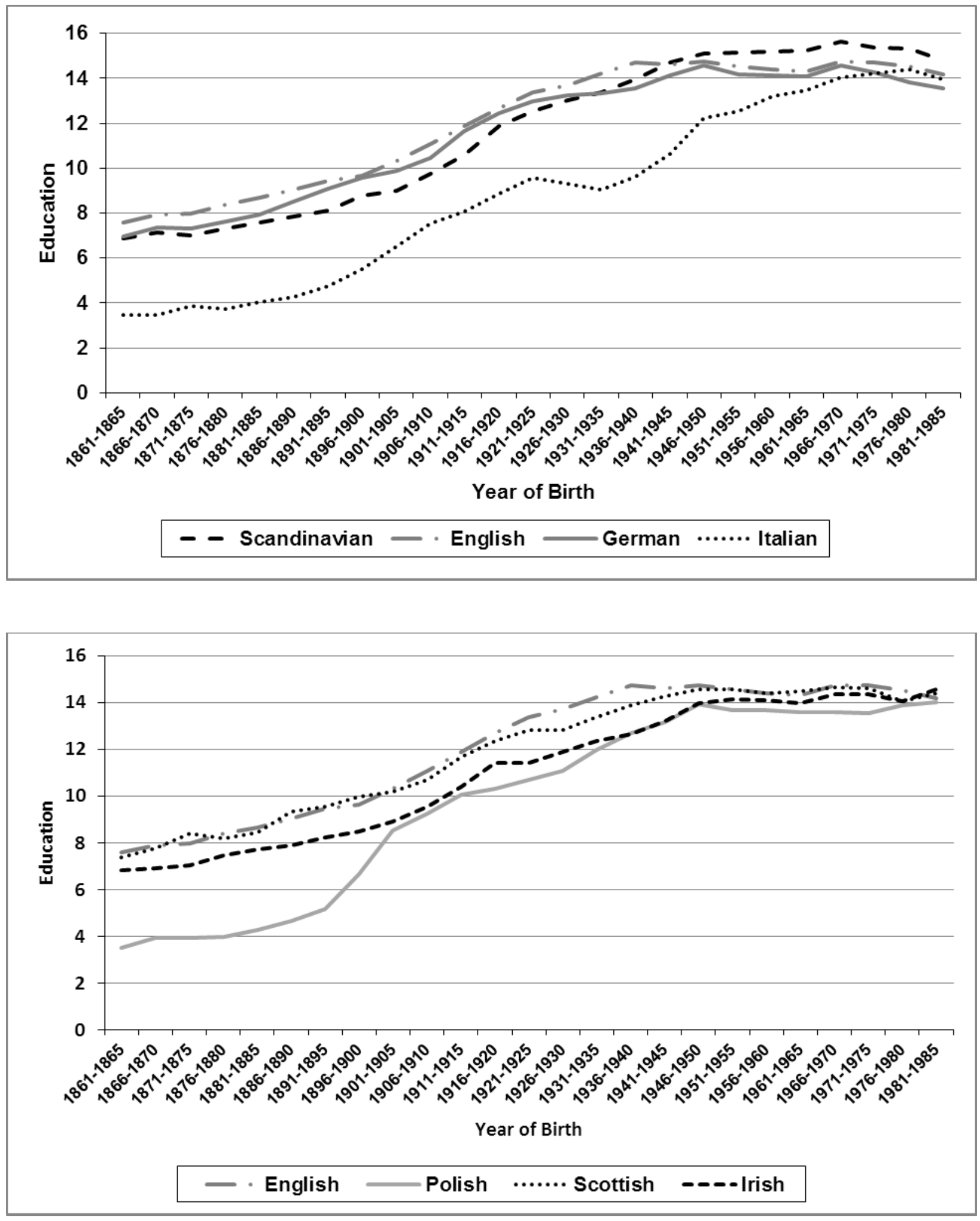
Figure 2. Education by Immigrant Generation by Year of Birth-Females
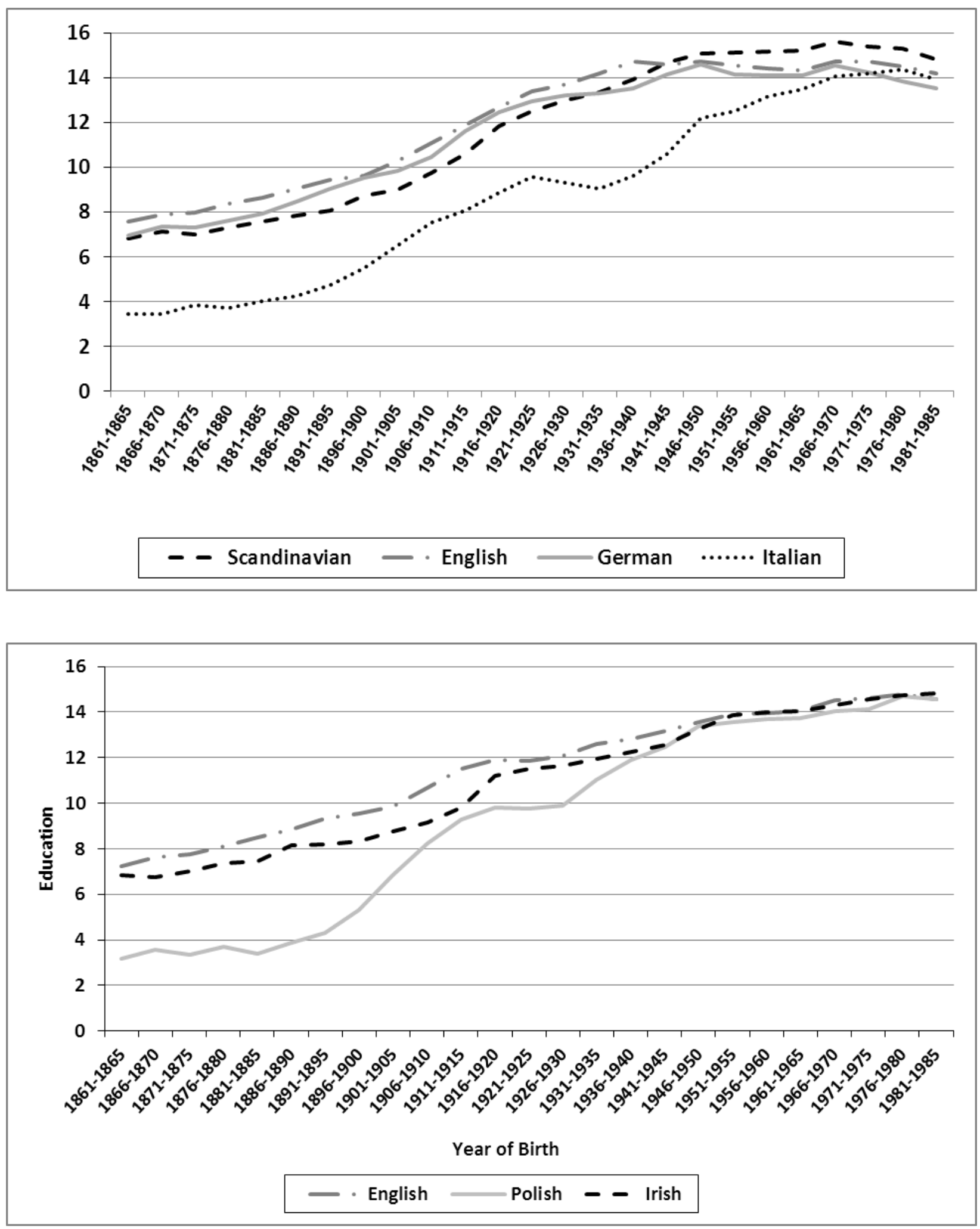
Figure 3.A. Education Gain of Second Generation Immigrants-Males
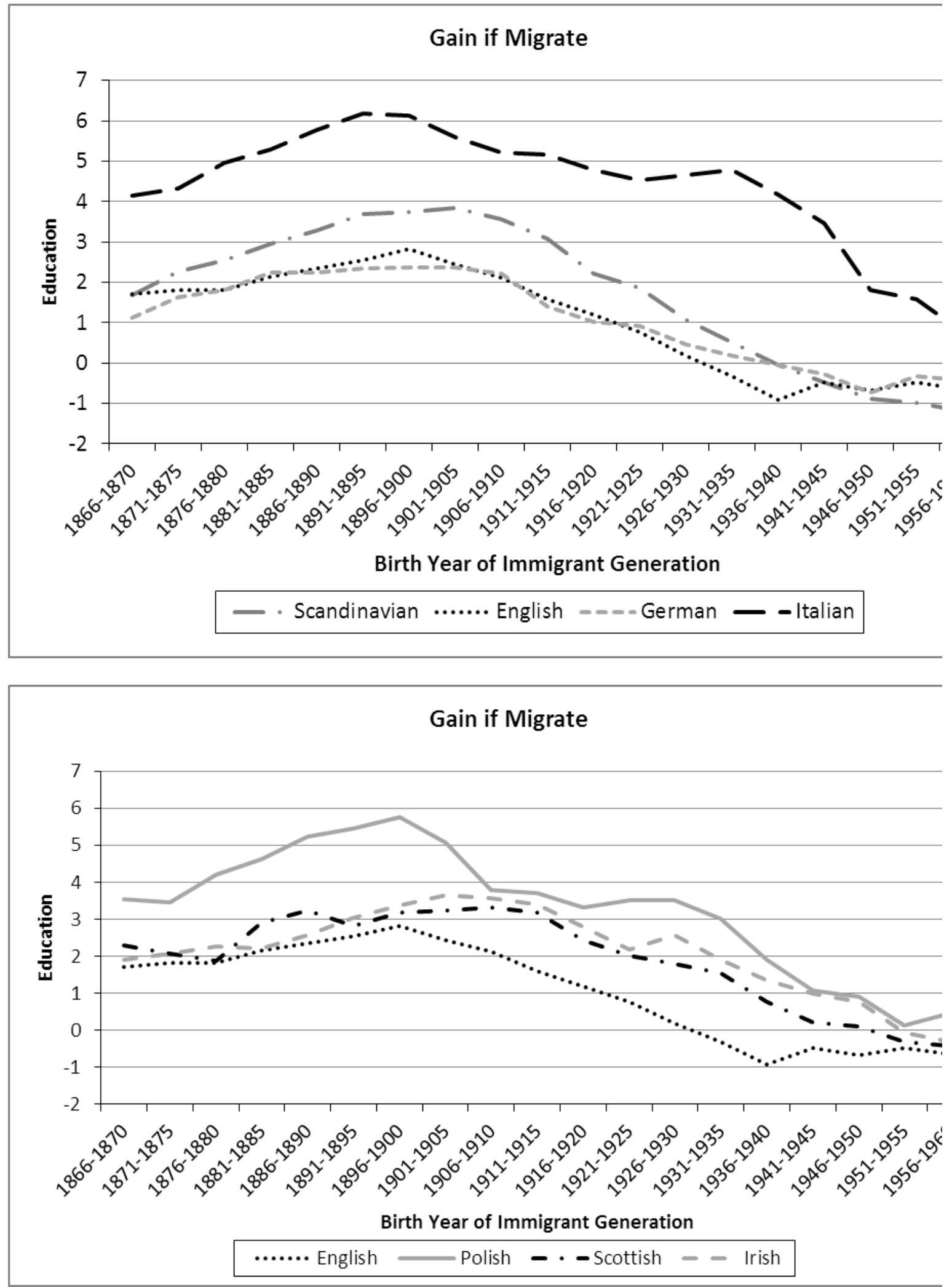
Figure 3.B. Education Gain of Second Generation Immigrants-Females
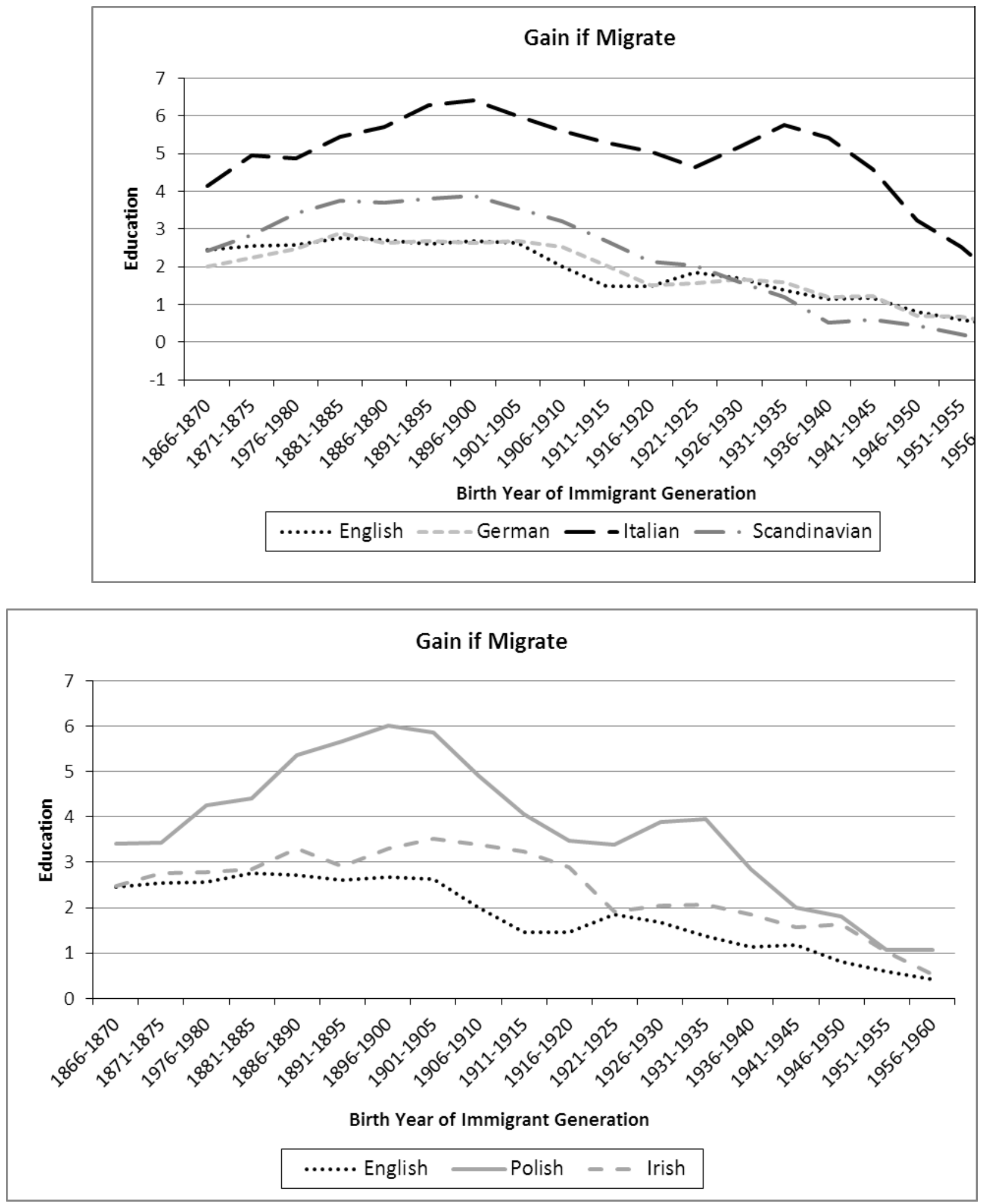
Figure 4.A. Education Gain of Second Generation Immigrants-Males

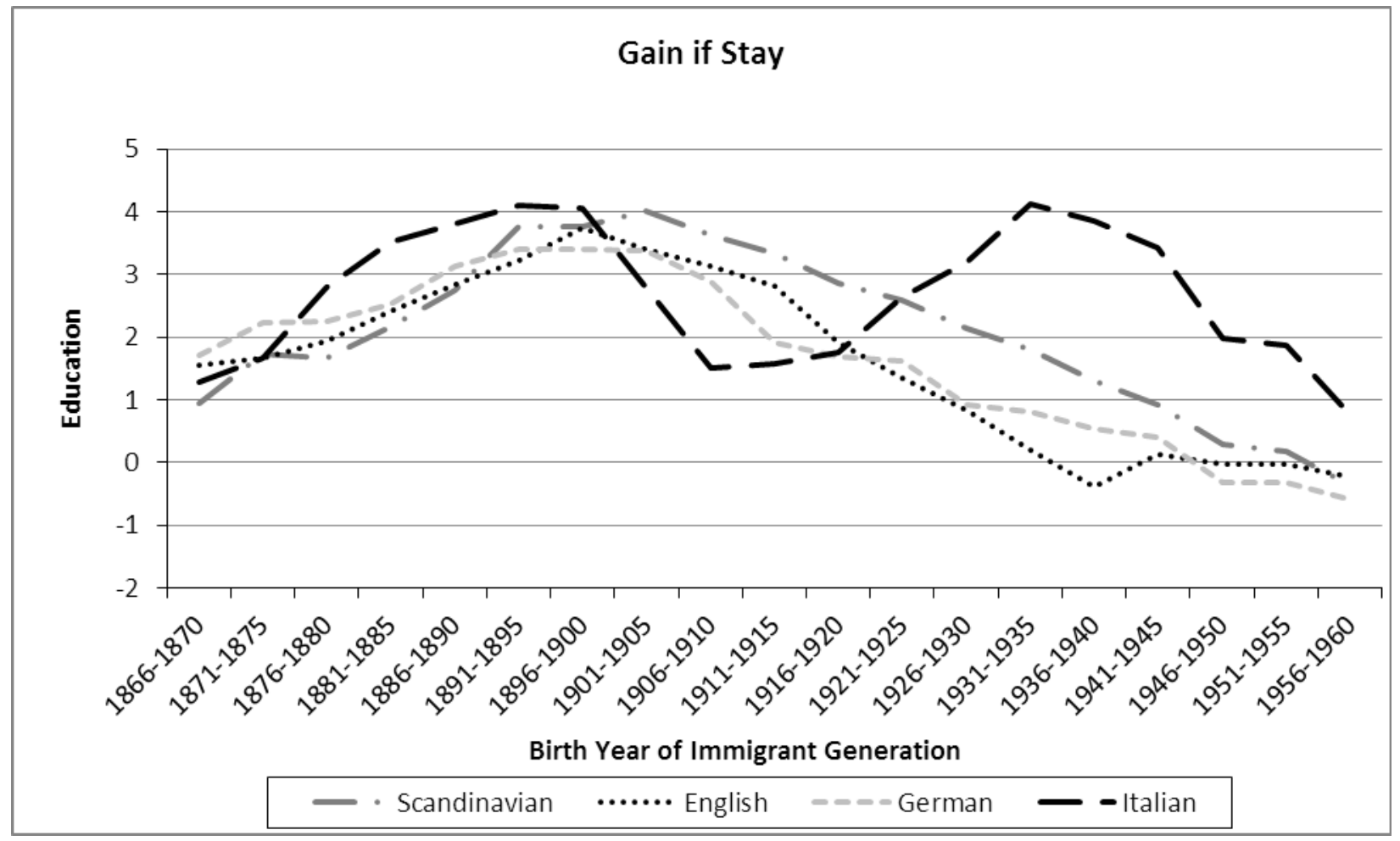

\section{Gain if Stay}

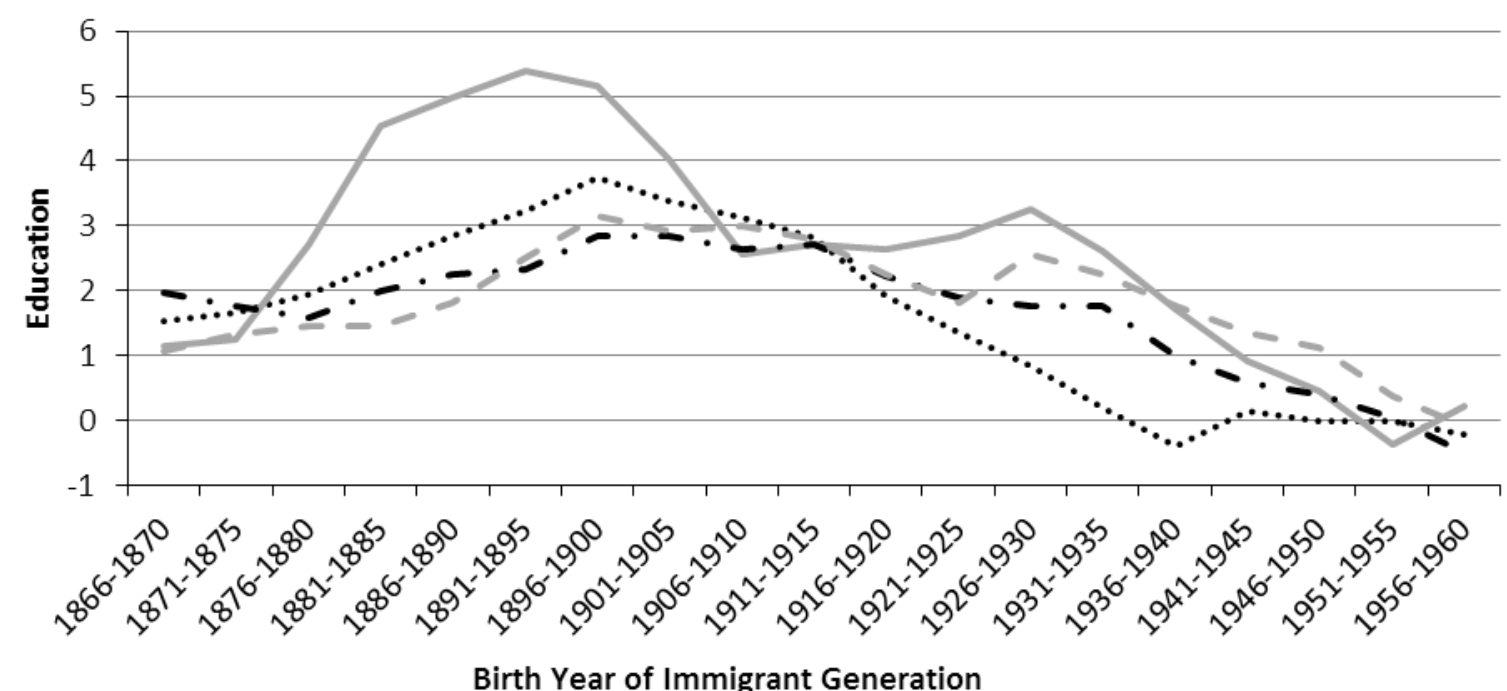

Birth Year of Immigrant Generation

...... English $\longrightarrow$ Polish - - Scottish - - Irish 
Figure 4.B. Education Gain of Second Generation Immigrants-Females
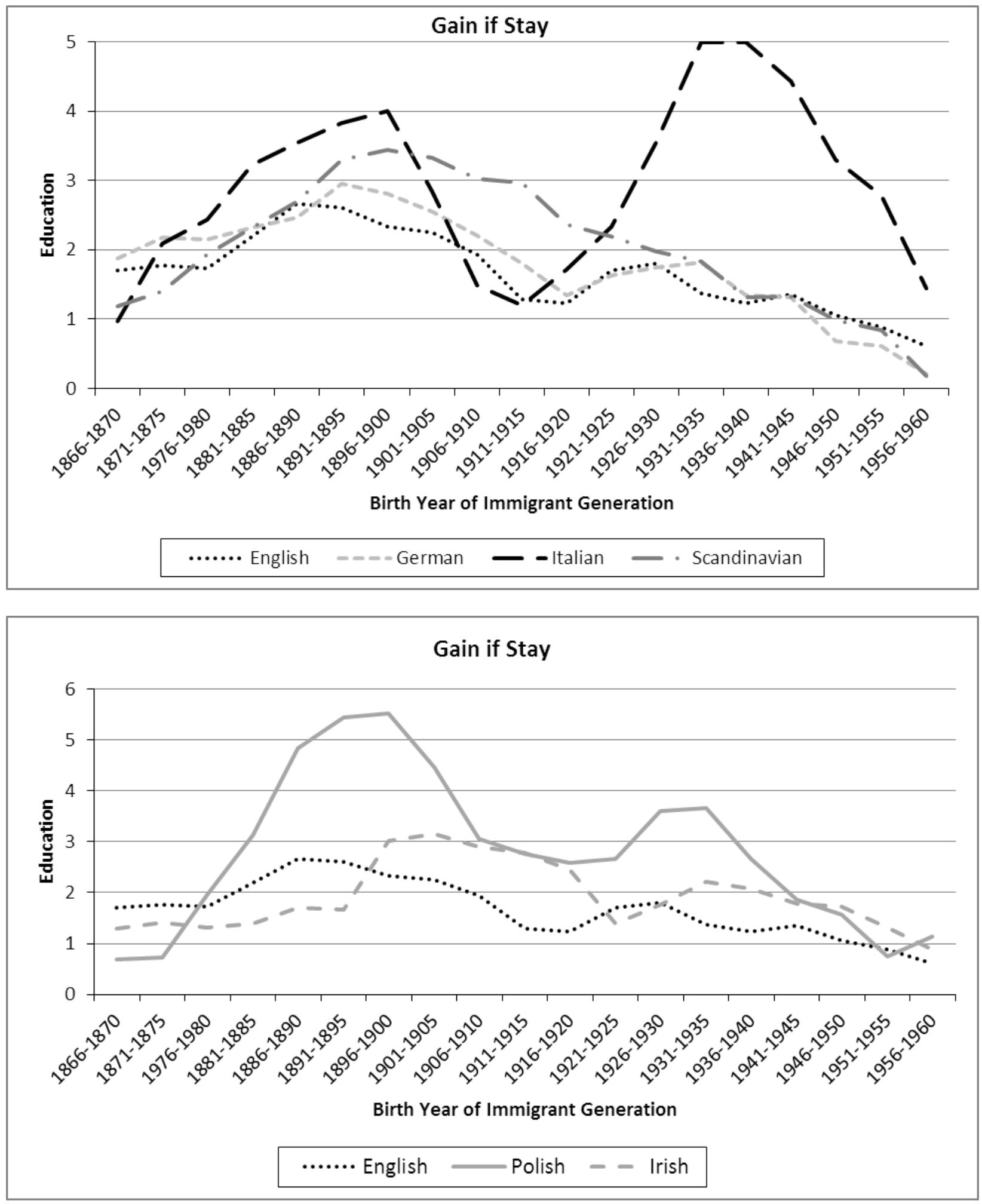
Figure 5.A. Education Gain of Second Generation Immigrants-Males
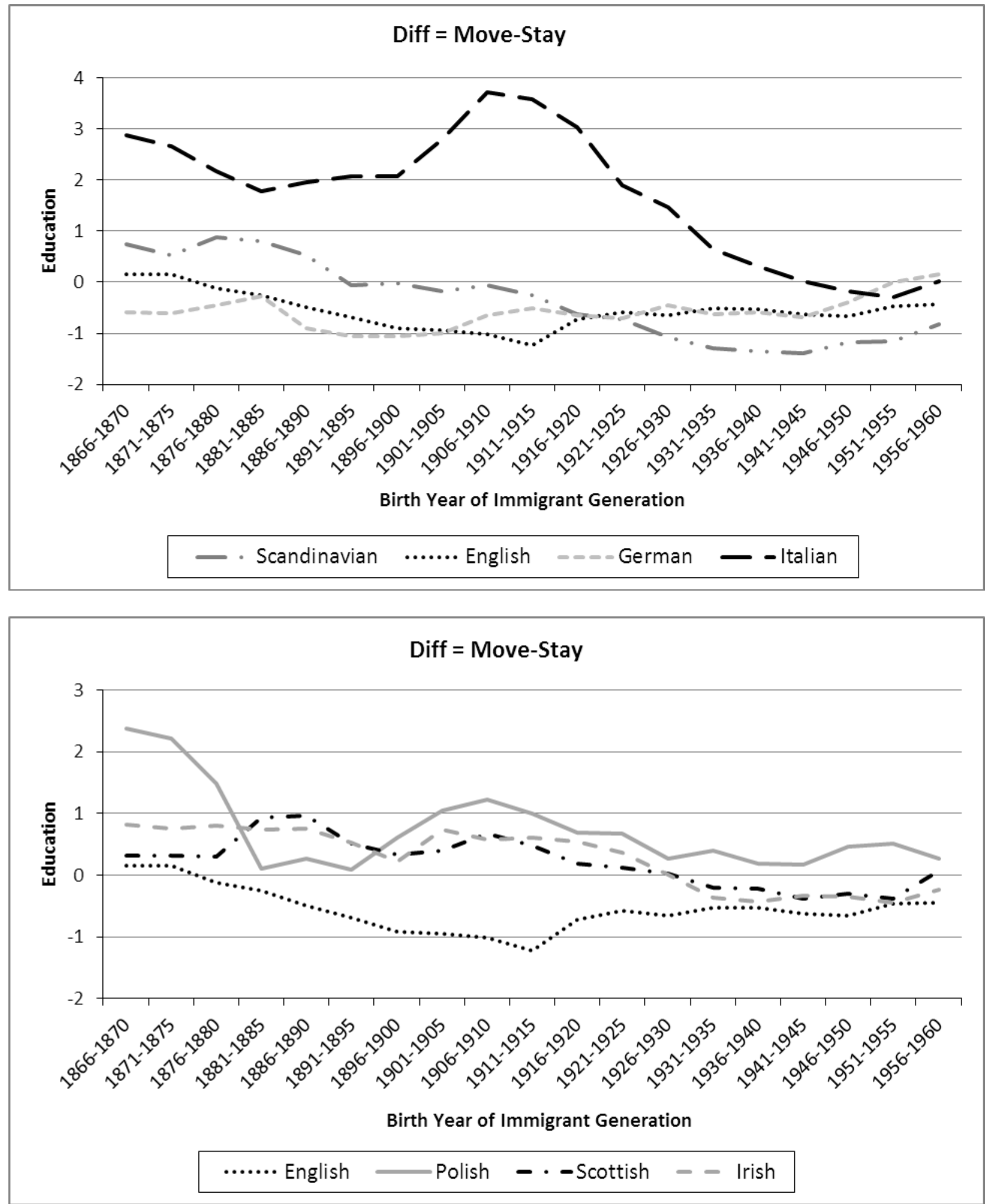
Figure 5.B. Education Gain of Second Generation Immigrants-Females
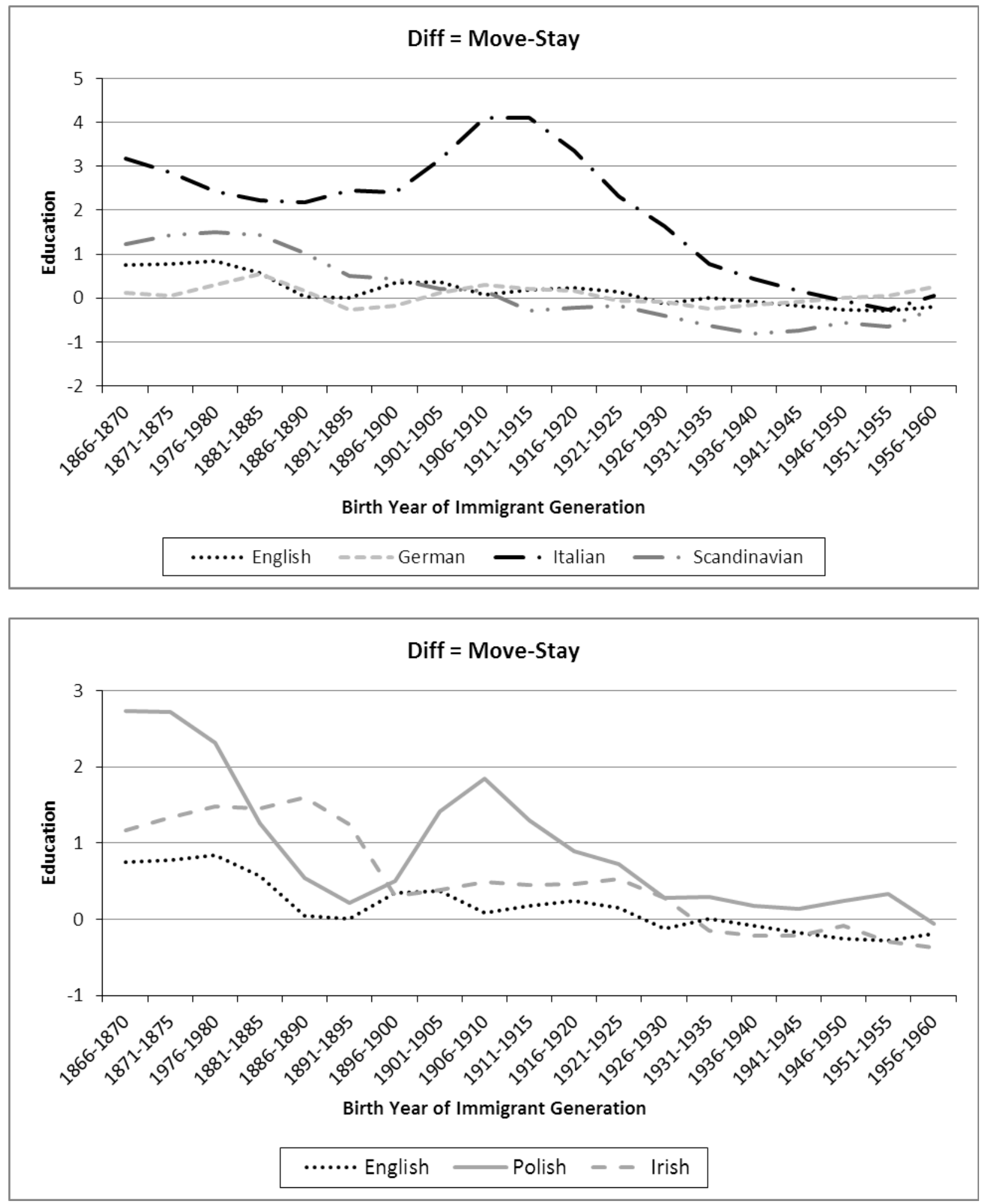
Figure 6.A Education Gain of $3^{\text {rd }}$ minus $1^{\text {st }}$ Generation Immigrants--Males
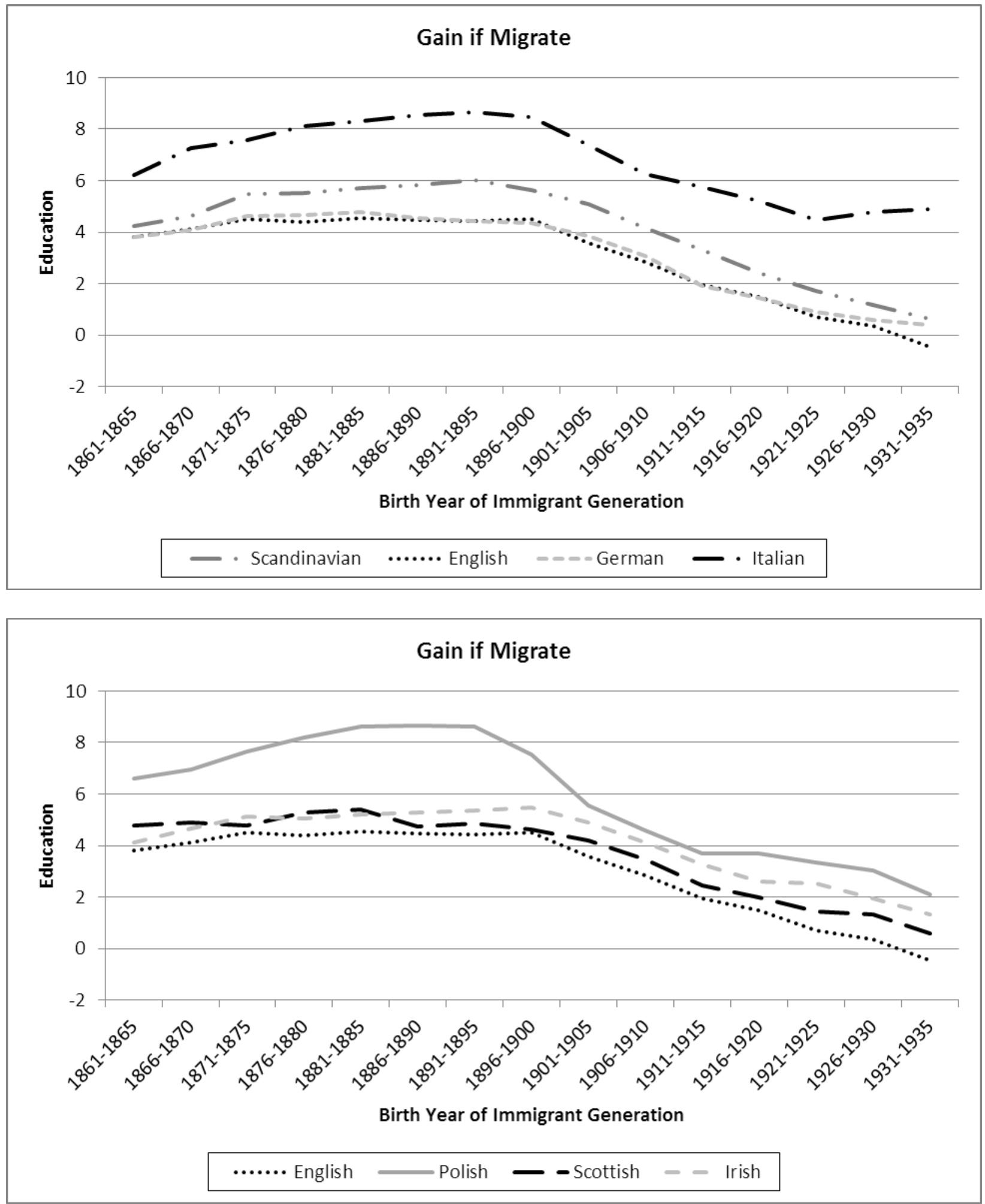
Figure 6. B Education Gain of $3^{\text {rd }}$ minus $1^{\text {st }}$ Generation Immigrants--Females
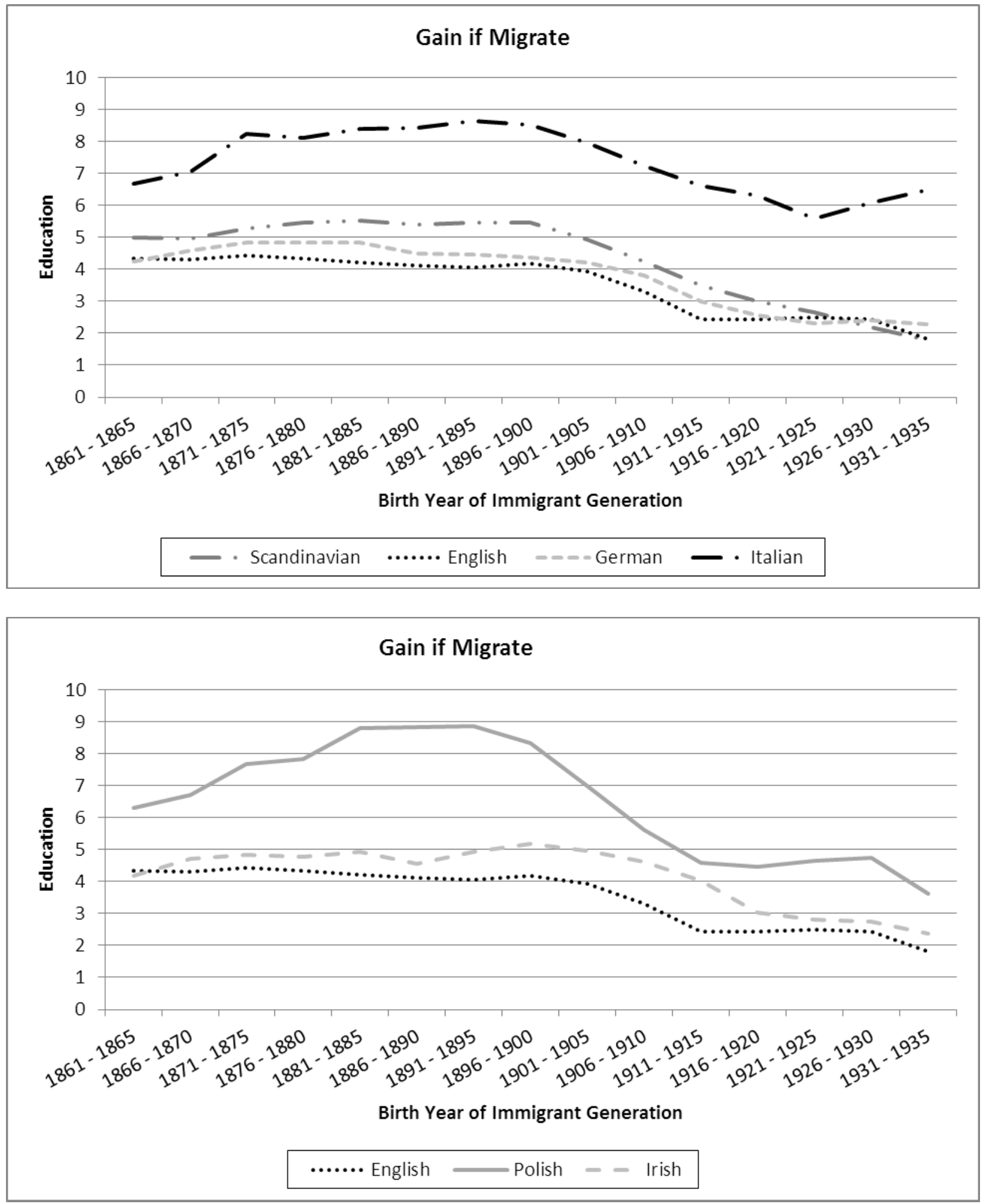
Figure 7.A Education Gain of $3^{\text {rd }}$ minus $1^{\text {st }}$ Generation Immigrants - Males
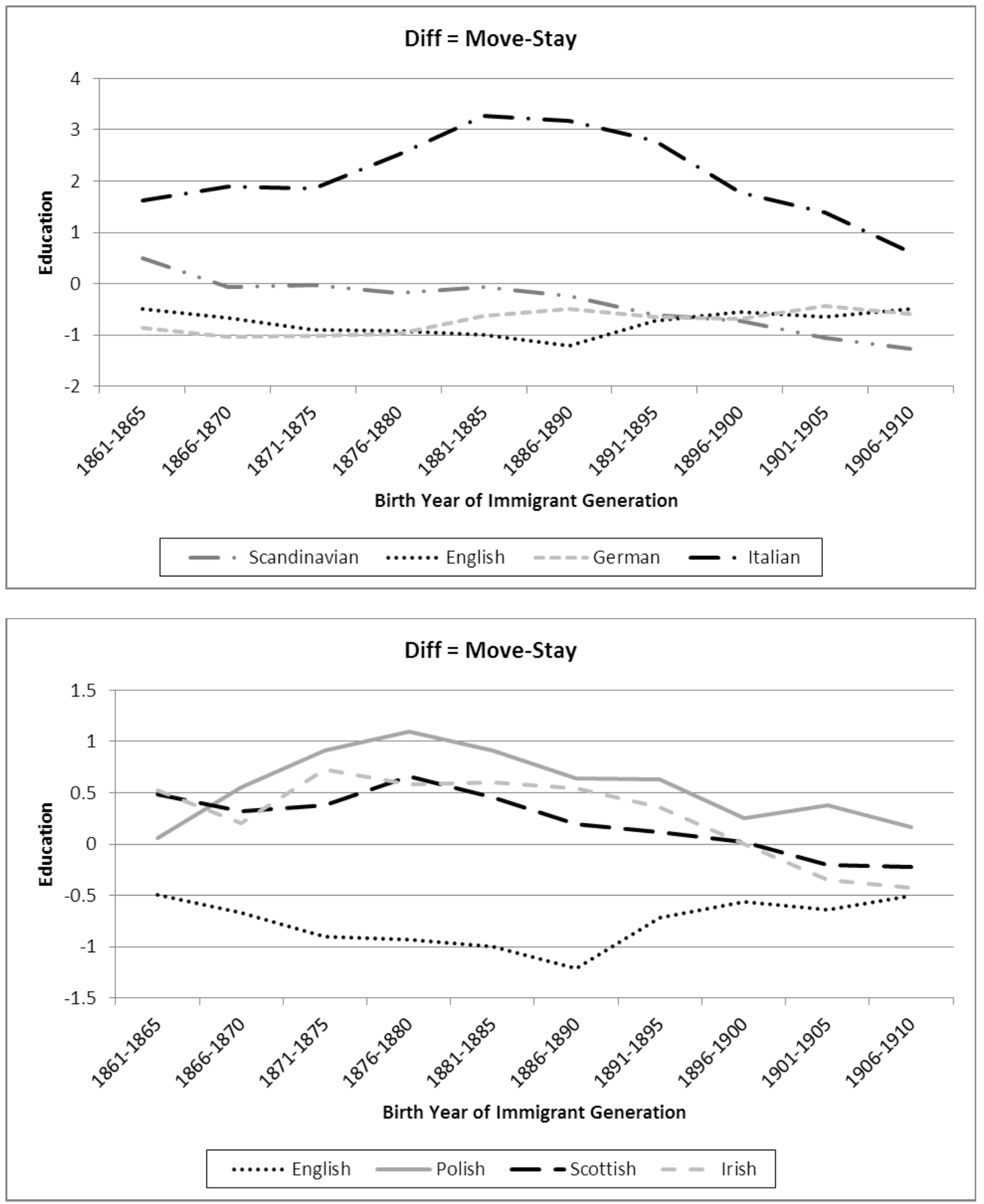
Figure 7. B Education Gain of $3^{\text {rd }}$ minus $1^{\text {st }}$ Generation Immigrants - Females
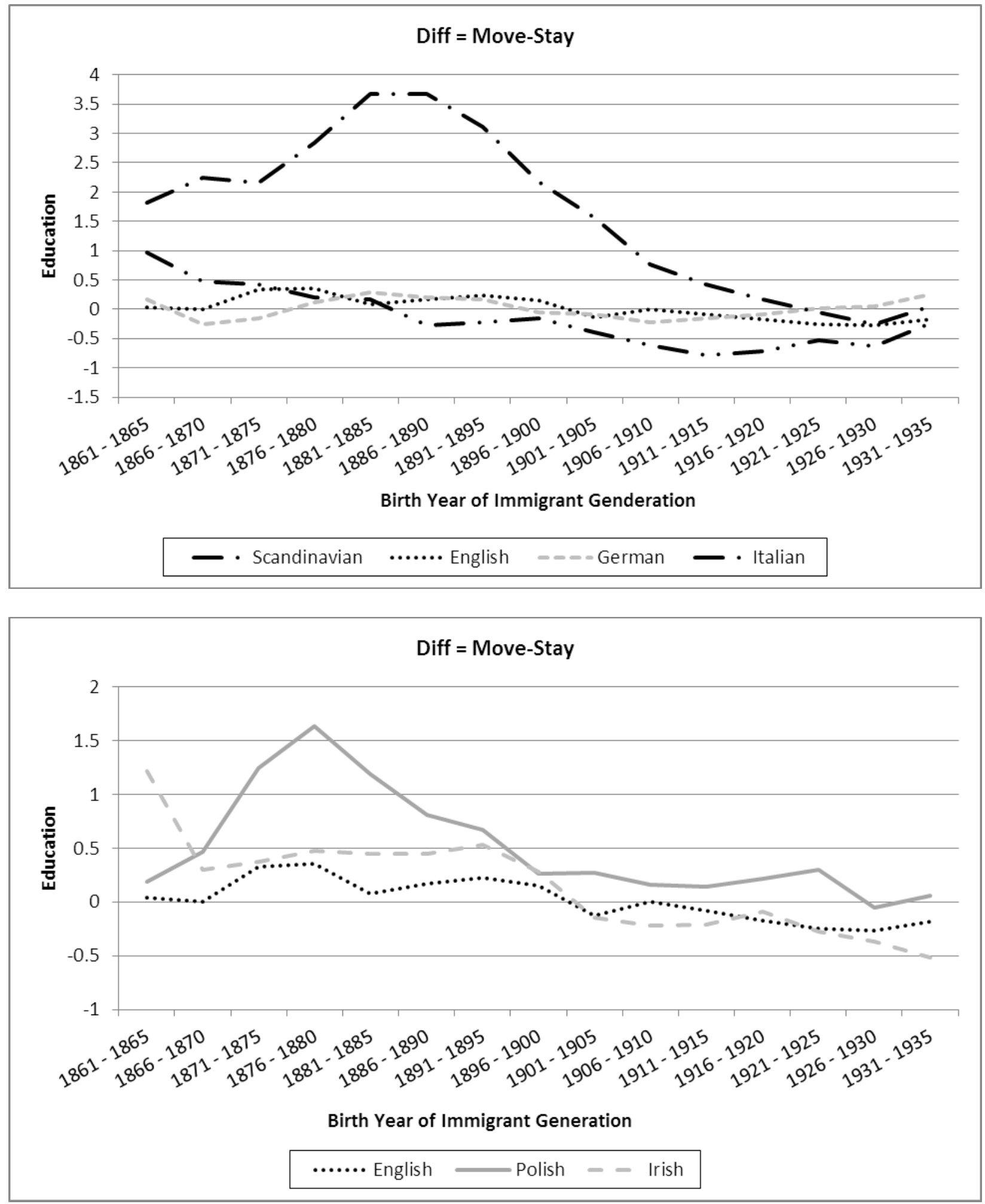
Fig. 8. Income of European Countries Relative to the United States

A. $\mathbf{1 8 7 0 - 2 0 0 0}$

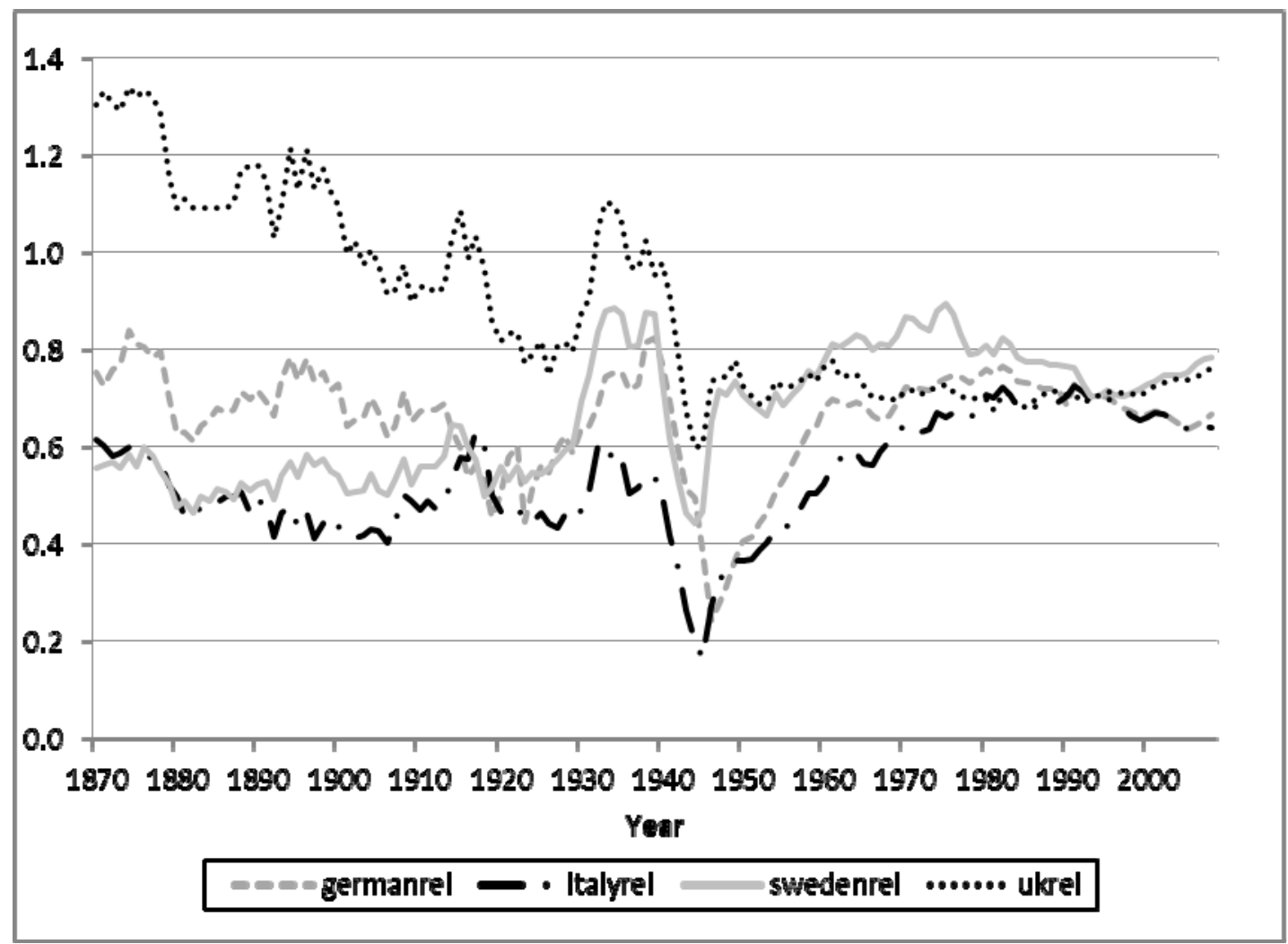

B. 1920-2000

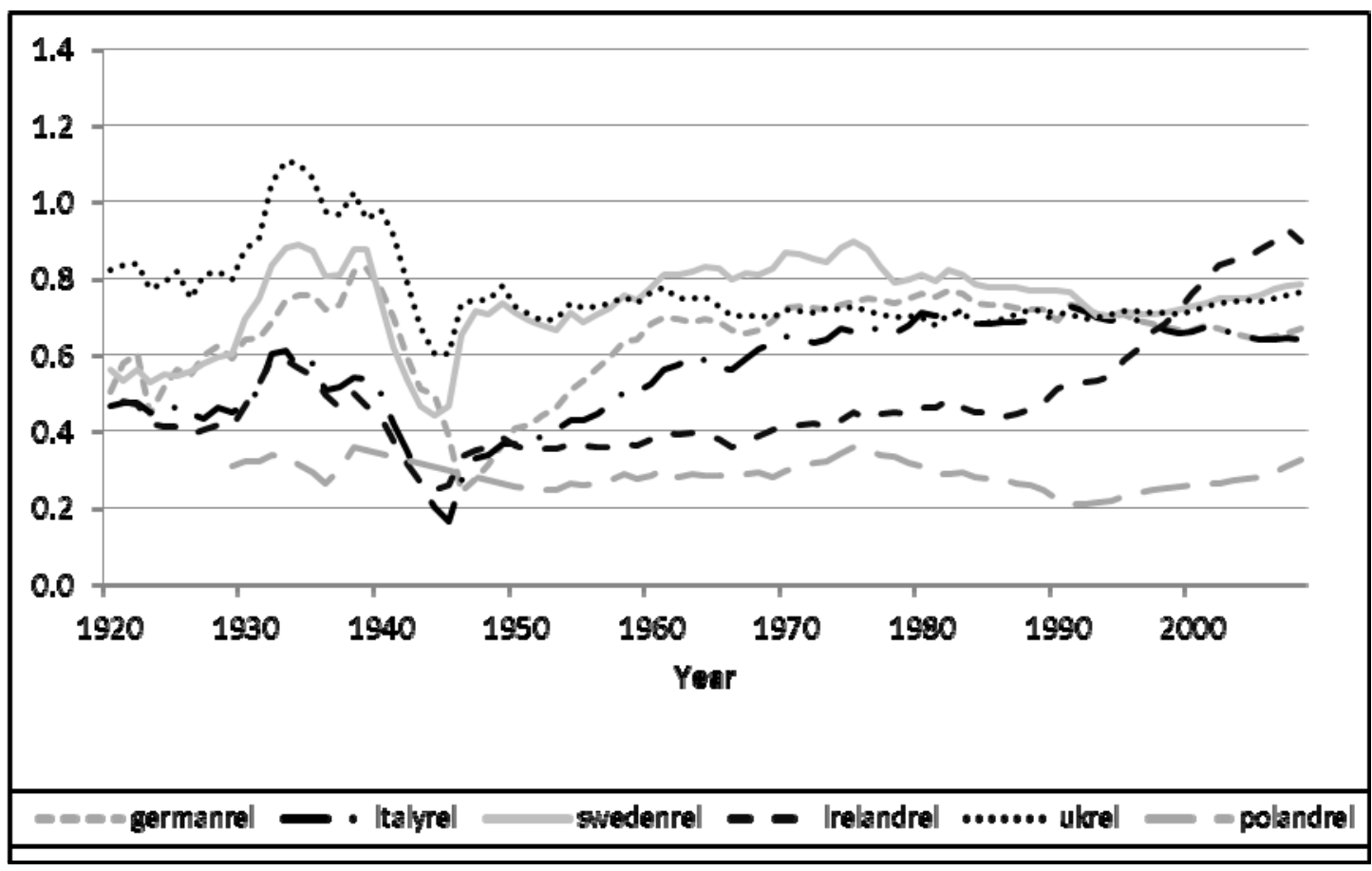


Figure 9. Income of European Countries Relative to the United States
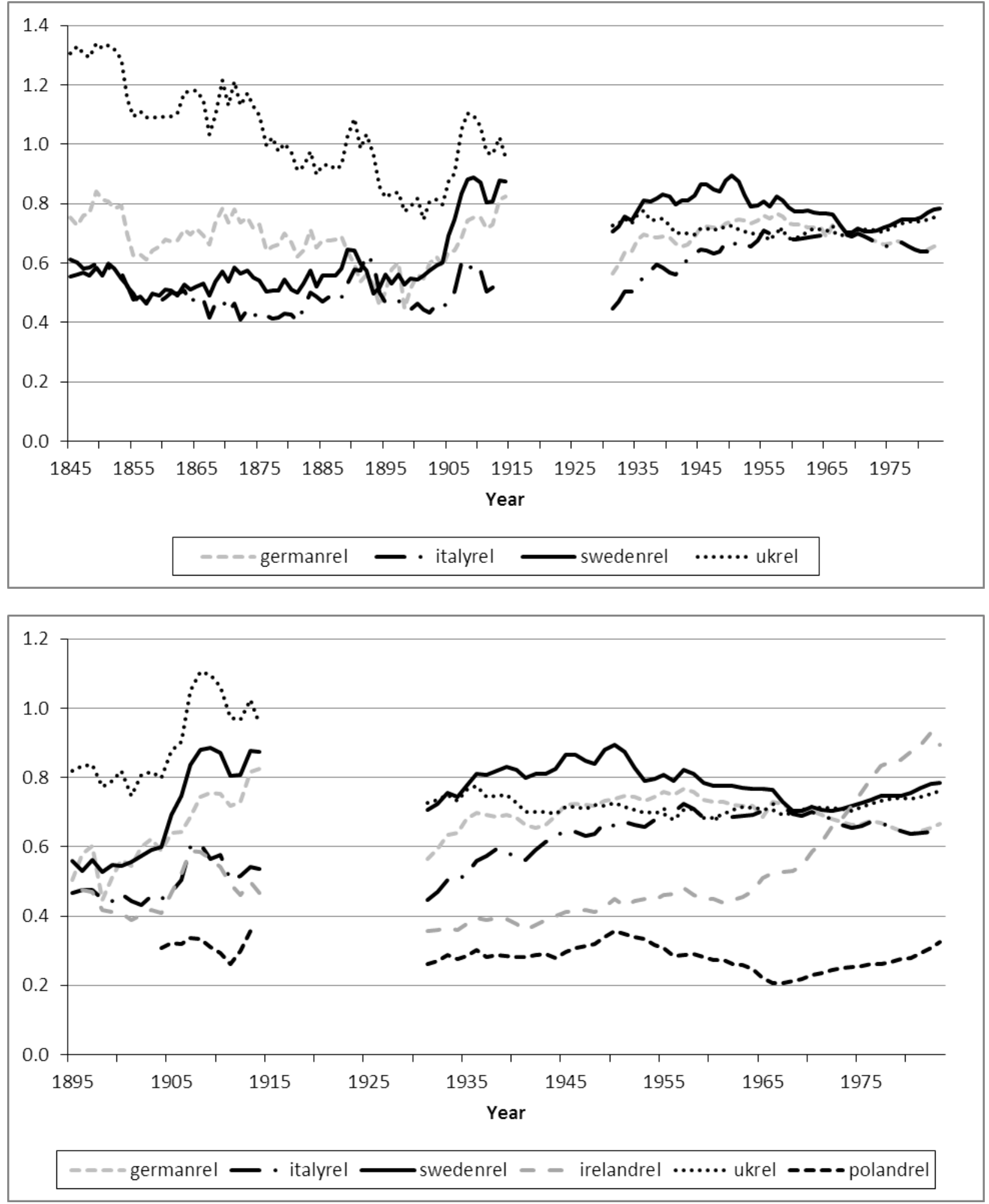


\section{Appendix Table A}

Data used to construct the European Generations

\begin{tabular}{|l|c|c|c|c|c|}
\hline & First & Second & Third plus & Fourth plus & $\begin{array}{c}\text { Third plus } \\
\text { by ethnicity }\end{array}$ \\
\hline 1940 Census & $\mathrm{X}$ & $\mathrm{X}$ & & & \\
\hline 1950 Census & $\mathrm{X}$ & $\mathrm{X}$ & & & \\
\hline 1960 Census & $\mathrm{X}$ & $\mathrm{X}$ & & & \\
\hline 1970 Census & $\mathrm{X}$ & $\mathrm{X}$ & & & \\
\hline $\begin{array}{l}\text { 1980-2000 } \\
\text { Census }\end{array}$ & $\mathrm{X}$ & Second plus & & & \\
\hline $\begin{array}{l}\text { CPS years } \\
\text { 1994-2006 }\end{array}$ & $\mathrm{X}$ & $\mathrm{X}$ & $\mathrm{X}$ & & \\
\hline $\begin{array}{l}\text { American } \\
\text { Community } \\
\text { Survey years } \\
\text { 2000-2008 }\end{array}$ & $\mathrm{X}$ & Second plus & & & \\
\hline $\begin{array}{l}\text { General Social } \\
\text { Survey years } \\
\text { 1994-2006 }\end{array}$ & $\mathrm{X}$ & $\mathrm{X}$ & $\mathrm{X}$ (Third only) & $\mathrm{X}$ & \\
\hline
\end{tabular}

